The directional volatility connectedness between crude oil and equity markets: New evidence from implied volatility indexes

Maghyereh, Al

http://hdl.handle.net/10026.1/4840

10.1016/j.eneco.2016.04.010

Energy Economics

All content in PEARL is protected by copyright law. Author manuscripts are made available in accordance with publisher policies. Please cite only the published version using the details provided on the item record or document. In the absence of an open licence (e.g. Creative Commons), permissions for further reuse of content should be sought from the publisher or author. 


\title{
The directional volatility connectedness between crude oil and equity markets: New evidence from implied volatility indexes
}

\author{
Aktham I. Maghyereh ${ }^{a}$, Basel Awartani ${ }^{\mathrm{b}, *}$, Elie Bouri ${ }^{\mathrm{c}}$ \\ a Department of Economics and Finance, United Arab Emirates University, United Arab Emirates \\ ${ }^{b}$ Plymouth Business School, Plymouth University, Plymouth, Devon, PL4 8AA, United Kingdom \\ c USEK Business School, Holy Spirit University of Kaslik, PO BOX 446, Jounieh, Lebanon
}

\section{A R T I C L E I N F O}

\section{Article history:}

Received 25 December 2015

Received in revised form 29 March 2016

Accepted 20 April 2016

Available online 29 April 2016

\section{JEL classification:}

C1

G1

Keywords:

Oil price volatility

Equity market volatility

Directional connectedness

Implied volatility indexes

\begin{abstract}
A B S T R A C T
In this paper, we use a set of newly introduced implied volatility indexes to investigate the directional connectedness between oil and equities in eleven major stock exchanges around the globe from 2008 to 2015. The inference on the oil-equity implied volatility relationships depends on Diebold and Yilmaz $(2012,2014,2015)$ who proposed a set of directional measures that enable the dynamic and directional characterization of the relationships among financial variables. We find uniform results across the sample countries indicating that the connectedness between oil and equity is established by the bi-directional information spillovers between the two markets. However, we find that the bulk of association is largely dominated by the transmissions from the oil market to equity markets and not the other way around. The pattern of transmissions is varying over the sample period; however most of the linkages between oil and equities are established from the mid of 2009 to the mid of 2012 which is a period that witnessed the start of global recovery.
\end{abstract}

(c) 2016 Elsevier B.V. All rights reserved.

\section{Introduction}

The relationship between oil and equity prices has attracted a lot of research. However, there have been a few studies that have focused on the relationship between oil and stock prices' volatility, particularly in the period following the financial global crisis. Moreover, most of research on the oil-equity relationship is based on statistical model volatilities and not on the volatilities used by the market to price options. In this paper, we examine the after crisis connectedness between oil implied volatility and equity implied volatilities in eleven major stock exchanges around the globe. ${ }^{1}$ To the best of our knowledge, this has not been done before in the oil-equity volatility relationship literature.

The study was not possible without the recently published crude oil implied volatility index (OVX) by the Chicago Board Options Exchange ( $\mathrm{CBOE}$ ) which has allowed for the investigation of the volatility connectedness between oil and equities that is implied by option market prices and not by historical returns. This type of analysis can provide another perspective on the association between oil and equities for many

\footnotetext{
* Corresponding author. Tel.: + 441752585587.

E-mail addresses: a.almaghaireh@uaeu.ac.ae (A.I. Maghyereh),

basel.awartani@plymouth.ac.uk (B. Awartani), eliebouri@usek.edu.lb (E. Bouri).

1 These countries are: USA, Canada, Japan, UK, Germany, Russia, Sweden, Switzerland, India, South Africa and Mexico.
}

reasons. First, implied volatilities are more accurate measures of the latent volatility process than either ARCH models or realized volatilities. $^{2}$ Second, as volatilities are derived from market option prices, they are forward looking and thus they represent the markets' consensus on the expected future uncertainty. The implied volatility linkages across markets are therefore informative about the relation between market participants' expectations of future uncertainty. This is important as it provides insights into ways of building accurate equity and option valuation models and improves forecasts of cross market volatility. Third, implied volatilities depend on fear and not only on the markets' expectations of future volatility. When fear is high, a risk premium follows and options are priced with higher volatilities than the volatilities used when fear is low. In that sense, the implied volatility analysis tracks the investors' sentiment and, therefore, the inferred volatility connectedness reflects fear connectedness that is expressed by market participants as they trade. ${ }^{3}$ Fourth, in the recent years and

\footnotetext{
2 See Blair et al. (2001) for more information about the in sample accuracy of implied volatility compared to other volatility. Furthermore, the studies of Christensen and Prabhala (1998), Fleming (1998), Jorion (1995), Blair et al. (2001) have all found evidence that implied volatilities are more accurate than historical model volatilities in the prediction of the latent volatility process.

${ }^{3}$ The most popular and monitored implied volatility index in the US is the VIX. It is touted as an investor fear gauge. In Whaley (2008), it is argued that the VIX is a barometer of investors' fear in a bear market and investors' excitement in a market rally.
} 
with the growing activity in the oil paper market, many financial market traders such as speculators, arbitrageurs, and convergence traders have started to invest in oil. These traders are highly leveraged and their trading is occasionally based on sentiment and risk aversion; their presence has hence intensified co-movements of risk across markets. The positive connectedness between oil and equities due to the change and increase in market participants is best captured by focusing on implied volatility linkages that account for cross market sentiments. Therefore, studying short term implied volatility connectedness may provide additional insights on the influence of the change in participants and trading activity on the linkages between oil and equity markets. ${ }^{4}$ Furthermore, the different nature of risk transfer between oil and equity markets is useful information for risk management and diversification in derivatives portfolios.

Hence, in this paper, we provide a recent picture about the risk transfer between oil and equities following 2008. We chose to start our estimation sample in 2008 because this year coincides with the beginning of the global financial crisis. Furthermore, during this period, the shale oil industry becomes a consolidated major player in the oil market. The period has also witnessed the collapse of cooperation among OPEC members, the slowdown of the biofuel industry, the Eurozone debt crisis and the slowdown of China which is a major source of incremental oil demand.

In principle, oil volatility can be interrelated with equity volatility through many channels. ${ }^{5}$ For instance, the recent plunge in oil prices to $\$ 27.62$ in January 2016 has dragged down the S\&P500 index by $9 \%$. This simultaneous drastic drop in oil and equity prices also reflects an association of volatility between the two markets. These linkages in volatilities are driven by many factors. The volatility in oil prices may cause corresponding variations in the earnings of oil related companies and, hence, uncertainty regarding the equity prices of these companies will increase. Similarly, the volatility of oil prices may cause volatility in the prices of banks and financial institutions that are exposed to oil and oil related companies. Depending on the extent to which volatility in the oil market reflects uncertainty regarding economic growth, it may cause volatilities in other equity markets to rise. The recent increase in the volatility of oil in January 2016 is caused by the heightened worries concerning the future growth of the Chinese economy; it was hence translated to high volatilities across global equity markets.

The bulk of research on the co-movement of oil focuses on oil price connectedness with equities. Little research has dealt with volatility spillovers. Moreover, the analysis in the studies that address risk transmission between oil and equities depends on statistical volatilities that are either model based or computed from historical returns. These volatilities are not accurate measures of the latent volatility such as the volatilities implied from option prices. ${ }^{6}$ Therefore, in this paper, we contribute to the literature by giving new insights on implied volatility spillovers following the global financial crisis.

In comparison with the related literature, our methodology is different and depends on a set of connectedness measures that are proposed by Diebold and Yilmaz $(2012,2014,2015)$. The biggest advantage of this method is that the proposed measures are dynamic and directional. For instance, according to these measures we may judge the extent of information transmission or volatility connectedness between

\footnotetext{
${ }^{4}$ For more information on this structural change and its impact on markets' linkages, see Kyle and Xiong (2001), Kodres and Pritsker (2002), Broner et al. (2006), Pavlova and Rigobon (2008), Danielsson et al. (2011), and Büyükșahin and Robe (2014)

${ }^{5}$ In terms of returns, there are many reasons why the oil market and equity markets may be interrelated. The higher oil prices can be translated into higher production costs lower productivity of labor and capital, lower household disposable income, lower demand for energy using durable goods and lower corporate earnings and equity prices. High prices can also mean higher earnings and equity values in the mining, oil, gas and other related industries (Nandha and Faff, 2008; El-Sharif et al., 2005). Or alternatively, it may have no influence whatsoever (Chen, 2010).

${ }^{6}$ For instance, the widely used ARCH models are found to explain less than $10 \%$ of the movement in the latent volatility and hence, the information content of these volatilities may be questionable (See Akgiray, 1989; Figlewski, 1997; Franses and Van Dijk, 1996; Brailsford and Faff, 1996).
}

oil and equities at any particular date. Moreover, as the measures are directional, they become revealing in terms of the origin of the bulk of informational transmission between the oil market and equity markets. Hence, the measures indicate which market is contributing the most to the connectedness of volatilities.

Our results show that the transmission of information between oil implied volatility and equity implied volatilities is bi-directional and asymmetric. In particular, we find that the directional connectedness from the oil market to equity markets is higher than the directional connectedness in the opposite direction. The highest pairwise volatility connectedness measure (26.9\%) is from oil to Canadian equities. The second and third highest connectednesses are from oil to the US and UK, where oil contribution amounts to $18.4 \%$ and $19.5 \%$ respectively. Moreover, oil was a net contributor of volatility to all stock markets under study. ${ }^{7}$

The dynamic analysis of connectedness clearly shows that the information transmissions from the crude oil uncertainty to other equity markets are more pronounced and larger in magnitude than the transmissions in the opposite direction. The nature of risk spillover during the sample period is characterized by a weak transmission at the beginning of the sample period (from Q1-2008 to Q2-2009). The risk transfer from oil to equities has picked up and increased from mid2009 to mid-2012. As we approached the end of the sample, oil transmission decreases. ${ }^{8}$ Over the entire sample period, the volatility transmission is dominated by the oil market.

Results from the Granger causality tests of implied volatilities are consistent with the directional connectedness measures. The direction of causality between implied volatilities of equity and oil markets is dominated by oil. The only exception is the US market where causality is found to be bi-directional. Finally, the dynamic conditional correlations show that correlations are average and varying across countries and time.

Our results are consistent with the bulk of literature that finds significant linkages between the oil volatility and equity volatilities. They conform nicely to the strand of literature that finds that the main information crosses are from the oil market to equity markets (Arouri et al., 2011; Awartani and Maghyereh, 2013; Bouri, 2015a,b; Bouri and Demirer, 2016; Malik and Hammoudeh, 2007; Malik and Ewing, 2009). However, we are different from all in terms of methodology and in that we focus on the linkages of implied volatilities that are used to price oil and equity options.

The rest of the paper is organized as follows: The next section summarizes the literature. Section 3 outlines the directional connectedness measures proposed by Diebold and Yilmaz (2015). Section 4 provides a description of the data set and some preliminary statistics of the implied volatility indices included in the study. In Section 5, we perform a full sample static analysis in which we characterize the connectedness among oil and equity volatilities. Also in this section, we perform a rolling sample analysis to check the dynamics of the connectedness across time. The robustness analysis is included in Section 6. The section presents the results of the Granger Causality tests and the dynamic conditional correlations. Finally Section 7 contains some concluding remarks.

\section{Literature review}

The literature on the oil equity relationship contains numerous studies. ${ }^{9}$ The early research of Kling (1985) indicates that oil price is

\footnotetext{
${ }^{7}$ The net total directional volatility transmission is only positive in the US and in the oil market. This indicates that these

two markets are net spillers of volatility to other equities.

${ }^{8}$ On the contrary, at the start of the sample in 2008 , the US dominates the information transmission with the oil market.

9 See Maghyereh (2004), Maghyereh and Al-Kandari (2007), Kilian (2008), Nandha and Faff (2008), Cong et al. (2008), Chen (2010), Arouri and Rault (2012), El-Sharif et al. (2005), Apergis and Miller (2009), Driesprong et al. (2008), Park and Ratti (2008); Hammoudeh and Aleisa (2004), Bachmeier (2008), Sari et al. (2010), Awartani and Maghyereh (2013), Mollick and Assefa (2013), Bouri (2015a, 2015b), Tsai (2015) and Bouri and Demirer (2016) among many others.
} 
negatively related to the performance of US equities. Similarly, the results of the present value model of Jones and Kaul (1996) finds that changes in oil prices may explain changes in equity returns in Canada, Japan, the UK and the US through the impact on current and futures cash flows. Other studies in the subsequent literature include Huang et al. (1996), Sadorsky (1999), Park and Ratti (2008), and Apergis and Miller (2009). These studies rely on various methodologies such as vector auto regression (VAR) models, international capital asset pricing models, integration tests and vector error correction models. They all arrive to a similar conclusion that oil price changes have an influence on equity returns. In the context of emerging markets, there are also a number of papers that have shown that oil shocks have long and short term impact on equity returns (Papapetrou, 2001; Basher and Sadorsky, 2006; Narayan and Narayan, 2010).

Motivated by the non-uniformity of impact of oil shocks on various sectors, some studies have examined the linkage with oil on a sector by sector basis. The studies by Sadorsky (2001), Boyer and Fillion (2007) show that share prices of Canadian oil and gas companies are positively related to the price of oil. The study by El-Sharif et al. (2005) shows that same results also apply for the gas and oil sector in the UK but to a lower extent. The work of Nandha and Faff (2008) produces similar results in the US. The significant impact of oil shocks on the transport sector in thirty eight developed countries is reported by Nandha and Brooks (2009).

In principle, there is a valid reason to believe that uncertainty in the oil markets may well introduce uncertainty in company earnings and reduce stock values. Hence, the oil-equity research contains some papers that assess the impact of oil price uncertainty on equity returns. For instance, the study of Nandha and Hammoudeh (2007) focuses on the association between market beta risk and equity returns in the presence of oil price and exchange rate uncertainty in the Asia-Pacific region. The multi-factor model used shows significant influence of oil price uncertainty in two of the countries of the sample. Similarly, the vector error correction model employed by Masih et al. (2011) shows a profound negative effect of oil volatility on South Korean equities. The impact of oil uncertainty on Eastern European equities is studied by Asteriou and Bashmakova (2013). They use a multi-factor model and find that the influence of oil price beta is negative and significant. The recent study of Wang et al. (2013) employs a structural VAR model and investigates the effect of oil price uncertainty on stock market returns. They find that both oil supply and demand uncertainty have negative effect on equity returns. All these studies suggest that oil price uncertainty is an important factor in determining stock market performance and volatility.

The aforementioned literature looks at the influence of oil price changes on the performance of equities without addressing the issue of volatility spillovers between oil and equities. This issue is addressed lately in the context of multivariate GARCH processes by another group of papers. Malik and Hammoudeh (2007) and Maghyereh and Awartani (2016) report significant transmissions of oil volatility to equity volatilities in Middle Eastern countries. The transmissions from equity volatility to oil volatility are found to be insignificant for all markets except for the Saudi market. Malik and Ewing (2009) find significant volatility transmissions between oil volatility and equity volatilities in the financials, industrials, consumer services, health care, and technology sectors in the US. Arouri et al. (2011) find significant volatility spillovers from oil to equities in Europe and the US and insignificant spillovers from equities to oil. Bouri (2015b) finds weak unidirectional volatility spillovers from oil prices to the Lebanese stock market.

Recently, Bouri (2015a) uses causality-in-variance tests and highlights the dynamic effects of the global financial crisis on the volatility transmissions between oil prices and stock indices of oil-importing countries. Whereas, Bouri and Demirer (2016) find unidirectional volatility transmissions from oil prices to emerging stock markets, particularly in the case of the net exporting nations of Kuwait, Saudi Arabia and UAE.
The studies above infer risk transmission by studying statistical volatilities that are either model based or computed from historical returns. Instead, in this paper, we contribute to the literature by giving new insights on risk transfer between oil and equities which is based on implied volatilities. The inference based on implied volatility is important as these volatilities are derived from market option prices and hence they represent the markets' consensus on the expected future uncertainty. Moreover, the implied volatility indexes are considered as gauges for fear and in that sense the inferred implied volatility connectedness reflects the fear connectedness that is expressed by traders and investors. Therefore, implied volatilities are more able to capture volatility crossovers that are related to market sentiment than historical volatilities. They are also more suitable to capture cross market fluctuations that are related to portfolio rebalancing and speculative activities that have increased recently in the oil paper market. ${ }^{10}$

In comparison with the related literature, our methodology is different and depends on a set of connectedness measures that are proposed by Diebold and Yilmaz. The advantage of this method is that it allows us to dynamically track down the extent of linkages as well as its direction. ${ }^{11}$ In the context of oil equity volatility spillovers, these measures are used by Awartani and Maghyereh (2013) who provided evidence that the volatility transmission mechanism in the GCC countries is dominated by volatility transmissions from the oil market. ${ }^{12}$

\section{Empirical methodology}

We utilize the directional connectedness measures that are introduced by Diebold and Yilmaz $(2012,2014,2015)$. The objective of this econometric technique is to compute various interesting measures from the transmissions of implied volatilities in a system that contains the oil market and the eleven equity markets included in the study. ${ }^{13}$

Assume that implied volatility indices, $I V_{i}$ are modeled as a vector autoregressive process, $\operatorname{VAR}(p)$ that can be written as ${ }^{14}$

$I V_{i}=\sum_{i=1}^{p} \Phi I V_{t-i}+\varepsilon_{t}$

where $\Phi$ is a $N \times N$ matrix of parameters to be estimated. Also assume that the vector of error terms $\varepsilon$ is independently and identically distributed with zero mean, and $\sum$ covariance matrix. If the VAR system above is covariance stationary, then there exists a moving average representation that is given by $I V_{t}=\sum_{i=0}^{\infty} A \varepsilon_{t-i}$, where the $N \times N$ coefficient matrices $A_{i}$ obey a recursion of the form $A_{i}=\Phi_{1} A_{i-1}+\Phi_{2} A_{i-2}+\ldots+\Phi_{p} A_{i-p}$ with $A_{0}$ is the $N \times N$ identity matrix and $A_{k}=0$ for $k<0$.

The moving average coefficients are important to understand the dynamics given that the variance decompositions are computed as transformation of the coefficients in the moving average representation above. The variance decompositions (or impulse responses) allow us to split the H-step ahead of forecast errors of each variable into parts that can be attributable to the various market shocks. The aggregation of these decompositions will be subsequently used to compute the directional connectedness of a particular market to any or to all of the markets under study.

\footnotetext{
10 The implied volatility as a forecast is also more accurate. For instance, the widely used ARCH models are found to explain less than $10 \%$ of the movement in the latent volatility and hence, the information content of these volatilities may be questionable (See Akgiray, 1989; Figlewski, 1997; Franses and Van Dijk, 1996; Brailsford and Faff, 1996).

11 These measures are recently proposed by Diebold and Yilmaz in a series of papers (Diebold and Yilmaz, 2009; Diebold and Yilmaz, 2012, Diebold and Yilmaz, 2014) and then unified in Diebold and Yilmaz (2015).

${ }^{12}$ The GCC stands for the Gulf Cooperation Council which is a group of oil producing countries that consists of Saudi Arabia, Oman, Kuwait, the United Arab Emirates, Bahrain and Qatar.

13 This procedure has been rapidly adopted in the relevant literature; refer for example to McMillan and Speight (2010), Antonakakis (2012), Awartani and Maghyereh (2013), Awartani et al. (2013), and Maghyereh et al. (2015).

${ }^{14}$ Note that the text and notation in this section are quoted from Diebold and Yilmaz (2012, 2014, 2015).
} 
The variance decompositions computation is usually done using orthogonal VAR shocks. The Cholesky identification scheme achieves orthogonality but the computed variance decompositions will then be unstable and dependent on the ordering of the markets. ${ }^{15}$ Thus, Cholesky decomposition is not suitable. A framework that produces invariant decompositions is the generalized VAR that allows correlated shocks and accounts for them appropriately. The framework has been first proposed by Koop et al. (1996) and Pesaran and Shin (1998) and is called the KPPS hereinafter. Following Diebold and Yilmaz, the KPPS H-step-ahead forecast error variance decompositions $\theta_{i j}^{\mathrm{g}}(H)$ for $H=1,2, \ldots$, is computed as ${ }^{16}$

$\theta_{i j}^{g}(H)=\frac{\sigma_{j j}^{-1} \sum_{h=0}^{H-1}\left(e_{i}^{\prime} A_{h} \sum e_{j}\right)^{2}}{\sum_{h=0}^{H-1}\left(e_{i}^{\prime} A_{h} \sum A_{h}^{\prime} e_{i}\right)}$

where $\sum$ is the variance matrix of the vector of errors $\varepsilon$, and $\sigma_{j j}$ is the standard deviation of the error term of the $j^{\text {th }}$ market. Finally, $e_{i}$ is a selection vector with one on the $i^{\text {th }}$ element, and zero otherwise. In order to get a unit sum of each row of the variance decomposition, Diebold and Yilmaz normalize each entry of the matrix by the row sum as ${ }^{17}$

$\theta \sim_{i j}^{g}(H)=\frac{\theta_{i j}^{g}(H)}{\sum_{j=1}^{N} \theta_{i j}^{g}(H)}$

Note the sum of decompositions across any particular market $\sum_{j=1}^{N} \tilde{\theta}_{i j}^{g}(H)=1$, and across markets $\sum_{i, j=1}^{N} \tilde{\theta}_{i j}^{g}(H)=N$. Therefore, $\tilde{\theta}_{i j}^{g}(H)$ can be seen as a natural measure of the pairwise directional connectedness from market $j$ to market $i$ at horizon $H$. To make Eq. (4) more intuitive, we use the notation $C_{i \leftarrow j}(H)$ to represent this transmission. In the same way, we also compute the pairwise directional connectedness in the opposite direction as $C_{j \leftarrow i}(H)$. The two statistics allow us to compute the net pairwise directional connectedness as

$C_{i j}=C_{i \leftarrow j}(H)-C_{i \leftarrow j}(H)$

These are interesting statistics that indicate which market is playing the dominant role in the information transmissions between the two markets.

In our case, we are particularly interested in determining how all markets together are contributing to a single market, so we aggregate partially. The total directional connectedness from all markets to market $i$, denoted by $C_{i \leftarrow \mathbf{}}(H)$, is computed as

$$
C_{i \leftarrow \square}(H)=\frac{\sum_{j=1}^{N} \tilde{\theta}_{i j}^{g}(H)}{\sum_{i, j=1}^{N} \tilde{\theta}_{i j}^{g}(H)} \times 100
$$

Using the same logic, we are also able to compute how a particular market $i$ is contributing to the shocks of all other markets by aggregating

\footnotetext{
15 Different orderings may result in significantly different spillover estimates (Klößner and Wagner, 2014).

16 In particular, the $\theta_{i j}^{\mathrm{g}}(H)$ represents the contribution of a one-standard deviation shock of $A_{j}$ to the variance of the $\mathrm{H}$ - step ahead forecast error of $A_{i}$.

17 Though the KPPS is robust to ordering, its decompositions do not sum up to one as in Cholesky factorization. Thus, the normalization of the sum will enable an intuitive computation of the contribution of a particular market, and an intuitive sum of contributions across markets.
}

partially. The total directional connectedness from market $i$ to all markets, denoted by $C_{\mathbf{m} \leftarrow i}(H)$, is computed as

$$
C_{\mathbf{I} \leftarrow i}(H)=\frac{\sum_{j=1}^{N} \tilde{\theta}_{j i}^{g}(H)}{\sum_{i, j=1}^{N} \tilde{\theta}_{j i}^{g}(H)} \times 100 .
$$

This is also an informative connectedness measure. Together with the previous statistics they may define the role of the market in the whole system of markets as a net transmitter or receiver of shocks. In particular, we are occasionally interested in computing the net total directional connectedness which can be calculated as

$C_{i}(H)=C_{\mathbf{M} \leftarrow i}(H)-C_{i \leftarrow \mathbf{M}}(H)$.

The total aggregation of the variance decompositions across all markets measures the system wide connectedness. The total connectedness in all markets is given by

$C(H)=\frac{\sum_{i, j=1}^{N} \tilde{\theta}_{i j}^{g}(H) \sum_{i, j=1}^{N} \tilde{\theta}_{i j}^{g}(H)}{\sum_{i, j=1}^{N} \tilde{\theta}_{i j}^{g}(H)}=\frac{N}{N}$

This represents only the ratio of the sum of all off diagonal elements in the variance decomposition matrix of all markets to the sum of all elements (off diagonal and own shocks). It also measures the total information flow among all markets under consideration.

\section{Data description and preliminary statistics}

\subsection{The implied volatility indexes}

The implied volatility indexes are termed as the VIX indexes and they are constructed and published by the CBOE. The VIX indexes are computed from the market prices of out-of-the-money calls and puts without the use of any pricing models. The indexes are calculated using the following formula:

$\sigma^{2}=\frac{2}{T} \sum_{i} \frac{\Delta K_{i}}{K_{i}^{2}} e^{R T} Q\left(K_{i}\right)-\frac{1}{T}\left[\frac{F}{K_{0}}-1\right]^{2}$

where $\sigma$ is defined as the $\mathrm{VIX} / 100$ and hence, the $\mathrm{VIX}=\sigma \times 100, T$ is the time to the maturity of the set of options, $F$ is the forward price level derived from the lowest call-put option premium difference, $R$ is the risk free interest rate, $\Delta K_{i}=\frac{K_{i+1}-K_{i-1}}{2}$ is a measure of the average interval between the strike price of the options adjacent to option $i$ and the strike price of optioni, $K_{0}$ is the first strike price below the forward price level $F$. Finally $Q\left(K_{i}\right)$ denotes the option premium computed as the mid-point of the bid-ask spread of each option with strike $K_{i}$.

The inclusion criteria into these indexes is designed such that it includes all out-of-the-money puts and calls that are centered around an at-the-money strike, $K_{0}$. However, if there are no bids for an out-ofthe-money option at a certain strike, then this option and all other options at higher (or lower in the case of puts) strikes are excluded from the computation of the index. Note that in high volatility markets, the demand for out-of-the-money options is strong and more options are included in the construction of the index.

Once the options from which the VIX is going to be constructed are selected, the weighting criterion of each option in the index is proportional to its premium and to the average distance of the strike of option with adjacent strikes that have non-zero bids. The option weight is also inversely proportional to the square of the option's strike.

To construct the index, the CBOE computes implied volatility using Eq. (9) for two sets of options: the near term options and the next near term options. Both sets last for more than 23 days but expire in 
less than 37 days. For instance, suppose that, in any one day, the two sets of options expire in 24 and 31 days respectively. Then, we compute Eq. (9) twice: once for the near term options with 24 days to maturity and another for the next near term options with 31 days to expiration. The VIX index which represents the 30-day volatility implied by option prices is interpolated from these two implied volatilities. Thus, the VIX index is a forward-looking measure of stock market volatility that investors might expected to see over the next 30 days (i.e., it represents what investors believe today volatility will be in the future).

From Eq. (9), we can see that the VIX index is computed without any option valuation model and in that sense it is model free. The VIX index is directly related to the market values of calls and puts and, hence, it reflects what the option traders think of future market volatility. The forward looking nature of option prices is the most important distinguishing feature of the VIX index. Accordingly, the implied volatility indexes have been shown to be more informative than historical volatility in terms of volatility measurement and prediction. ${ }^{18}$

\subsection{Preliminary statistics}

As mentioned previously, to understand the cross transmission of volatility between oil and major equity markets, we use implied volatility indices. The volatility used to price options not only includes the consensus of the market regarding future volatility but is also more accurate and contains a premium for fear. Therefore, these indices are more suitable in our context than realized or historical volatility measures that are less informative on the latent volatility and do not account for fear.

The implied volatility indices for crude oil and other 11 major countries around the globe are collected from Thomson Reuters DataStream. The countries are: USA, Canada, UK, India, Mexico, Japan, Sweden, Russia, South Africa, Germany and Switzerland. Data comprise daily closing price and the symbols of the indices under study are: OVX for crude oil, AEXVOLI for USA, VIXCVOLI for Canada, VFTSEIX for the UK, NIFVIXI for India, VIMEXVI for Mexico, VXJINDX for Japan, SIXVXVL for Sweden, RTSVXVL for Russia, JSAVIVI for South Africa, VDAXNEW for Germany, and finally VSMI01M for Switzerland.

As the crude oil implied-volatility index is only available after the 3rd of March 2008, our sample is restricted and only covers the period that is following the 3rd of March 2008. It extends to the 3rd of February 2015 for a total of 1806 daily observations. Hence, in this paper, we provide a recent picture about risk transfer from oil to equities following the global financial crisis. The period under study has also witnessed the rise in the oil paper market where many equity investors have started to invest in oil. The presence of these traders in both the equity and oil markets may have implications on risk transfer and linkages between oil and equities.

Fig. 1 displays the time series plot of the implied volatility indices over the sample period. As can be seen in the figure, the volatilities with which oil and equity options are priced move closely together across time. Moreover, the implied volatilities of oil and equities show common spikes. For instance, volatilities spike around the mid of 2008 and during the global financial turmoil which has created big uncertainties about future global growth, demand for oil and equity markets' performance. Similarly large revisions of oil and equity volatility predictions occur towards the end of 2009 due to the increased uncertainty of the Greek sovereign debt crisis. Another common spike in oil and equity market implied volatilities occurred near the beginning of 2011 as worries over the sovereign debt and banking problems in Italy and Spain mounted.

The common trends in implied volatilities are not surprising as oil and equity price changes were severe during that sample period. For instance, the price of crude oil dropped from a high of $\$ 146$ per barrel to a low of $\$ 39$ with the financial meltdown that started with the collapse of

\footnotetext{
18 See for instance, Poon and Granger (2003), Whaley (2008), Carr and Wu (2006), Corrado and Miller (2005), Bentes (2015), and Gonzalez-Perez (2015).
}

Lehman Brothers in August 2008. Unlike equities which recovered slowly, oil has fastly recouped its losses and reached nearly $\$ 100$ in early 2010. This was due to the continued strong demand from emerging economies and China. Opposite to the US and most European Union countries that slowed down, these economies surprisingly continued to grow at a high pace despite the financial crisis. Equities have also experienced large price fluctuations during the sample period. They dropped significantly over the various stages of the global financial crisis following 2008 all the way to mid-2009, and then, after a slight recovery, they experienced big variations with the European Sovereign debt crisis that started in Greece in late 2009 and early 2010 and folded only recently.

However, the common trends in volatilities between oil and equity were broken by the end of the sample in 2014 and 2015. Fig. 1 shows that in July 2014 there was a spike in the volatility of prices of shortterm oil options that was not matched by the volatility of pricing equity options. This indicates that oil volatility in the recent years is more driven by the factors that are less likely to influence equity markets and equity volatilities. These factors are related to the fundamentals of oil as a commodity and to the increase in shale oil production as well as the plentiful global supplies that led to big declines in oil prices. ${ }^{19}$

It is worth to mention here the increase in the inter-relationships observed recently. The severe drop in oil prices in January 2016 to $\$ 27$ has led to big losses in global equity markets. For instance, the S\&P500 has lost $9 \%$ of its value on the same day. This demonstrates clearly how oil volatility is intertwined with equity volatility, particularly when oil volatility reflects news that is crossing to other markets. The recent drop in oil prices revealed the likelihood of a Chinese slowdown and therefore it increased stock market uncertainty.

To compare the statistical properties of the data under study, we computed a variety of summary statistics. Table 1 Panel A and Panel B report the summary statistics of the levels and the log changes of implied volatility indices of crude oil and equity markets respectively. Panel A displays the mean, the standard error, the minimum, the maximum, the skewness, the excess kurtosis and the Jarque-Bera statistics. Later statistics are used to test the null hypothesis that implied volatility forecasts are normally distributed. On average the panel shows that the level of crude oil implied volatility and its standard error are higher than equity markets. The higher average level indicates that crude oil options are priced with higher volatilities than equity options in all investigated markets. The higher standard error shows that the implied volatility is more volatile in the crude oil market than in the equity markets. This suggests that the markets are more confident in predicting equity volatility than oil volatility. The higher standard error is also reflected in a wider range of the oil index compared to equity indices as indicated by the minimum and maximum levels in Table 1 . The only exceptional market is Russia which exhibited higher volatility and standard errors in volatility levels compared to oil. The log volatility changes in Panel B point out that, over the sample period, the net change in market expectation of equity implied volatilities are negative in all equity markets, and positive in the oil market. Hence, the volatility with which options are priced has increased on average for oil options, while it has decreased for equity options over the sample period..$^{20}$

Table 1 also shows that the distributional properties of the oil implied volatility index is far from being normal. The index is positively skewed and leptokurtic and the Jarque-Bera statistics rejects the null hypothesis of normality very strongly. The skewness and kurtosis of the index indicates serious upward volatility revisions in pricing oil options during the sample period. The distributional properties of the

\footnotetext{
19 The oil traded above $\$ 100$ per barrel until the end of July, 2014. At that point, prices started to collapse falling to approximately $\$ 44$ by March 2015 . The OPEC announcement on November 27, 2014 to hold crude oil supplies steady at 30 million barrels per day led to an $11.2 \%$ decline in the price of the crude in that day alone. The recent slowdown of the Chinese economy has also contributed to weakening the oil market.

${ }^{20}$ The exception was Russia where the log changes in volatility was positive over the sample period.
} 

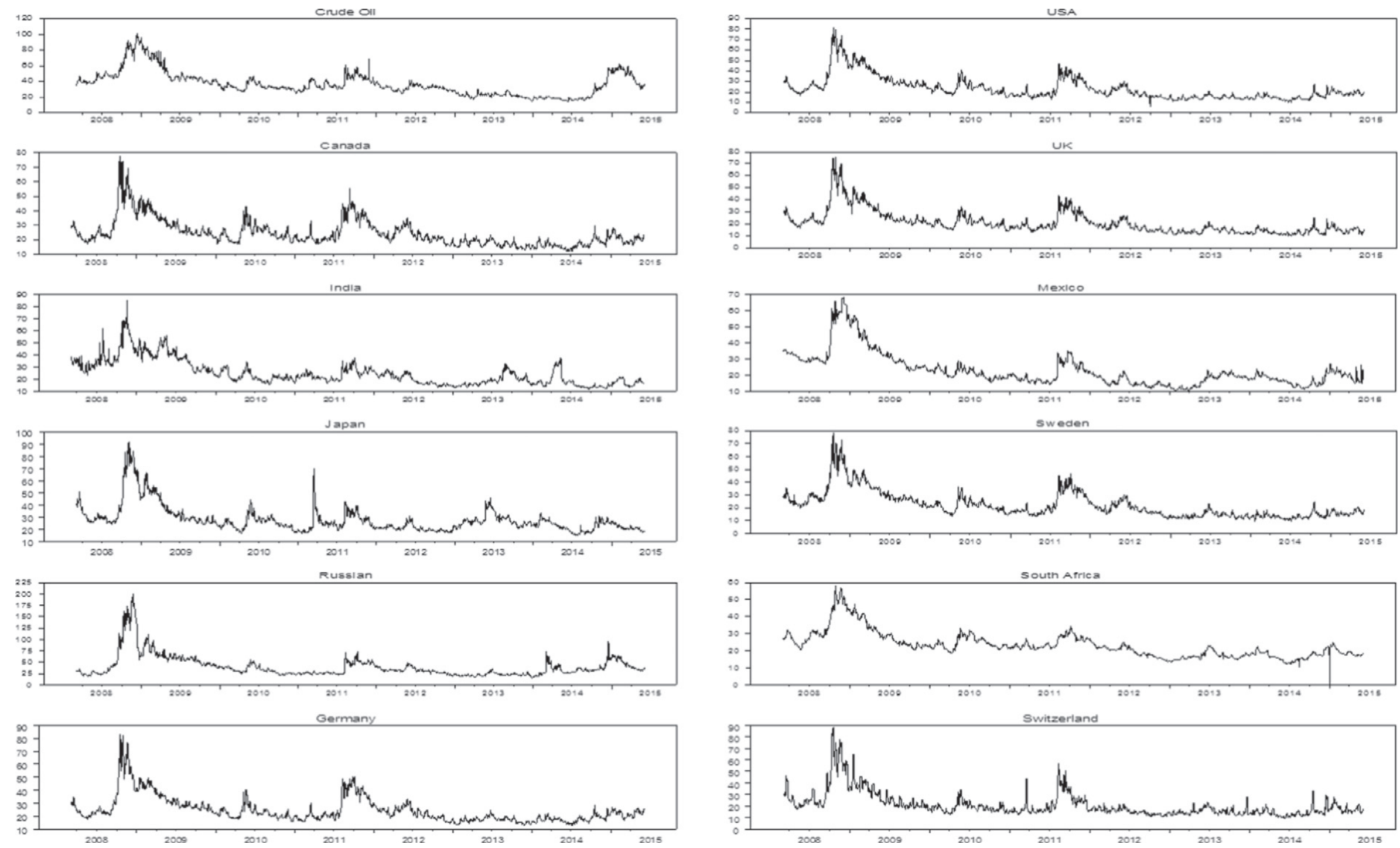

Notes: This figure shows the time series plot of the implied volatility indices of crude oil and stock markets over the sample period from $3^{\text {rd }}$ of March 2008 to 3rd February 2015. 
Table 1

Descriptive statistics of the implied volatility indices.

\begin{tabular}{|c|c|c|c|c|c|c|c|c|c|c|}
\hline & Mean & Std. Dev. & Min & Max & Skewness & Kurtosis & Jarque-Bera & $\mathrm{Q}(20)$ & ADF constant & ADF intercept and trend \\
\hline \multicolumn{11}{|l|}{ Panel A: Levels } \\
\hline Crude oil & 37.011 & 15.401 & 14.500 & 100.420 & 1.334 & 2.228 & $953.030^{* * *}$ & $33,901.900^{* * *}$ & -2.592 & -3.111 \\
\hline USA & 23.310 & 11.047 & 5.770 & 81.220 & 1.932 & 4.406 & $2708.800^{* * *}$ & $31,454.800^{* * *}$ & $-3.258^{* *}$ & $-4.107^{* *}$ \\
\hline Canada & 24.261 & 9.201 & 11.819 & 78.050 & 1.908 & 5.051 & $3160.900^{* * *}$ & $28,392.200^{* * *}$ & $-4.122^{* * *}$ & $-4.917^{* * *}$ \\
\hline UK & 20.936 & 9.538 & 9.672 & 75.540 & 2.108 & 5.943 & $4187.100^{* * *}$ & $29,700.700^{* * * *}$ & $-3.686^{* * *}$ & $-4.771^{* * *}$ \\
\hline India & 24.636 & 10.331 & 11.560 & 85.130 & 1.549 & 2.898 & $1419.500^{* * *}$ & $30,991.100^{* * *}$ & $-3.181^{* *}$ & $-4.384^{* *}$ \\
\hline Mexico & 22.744 & 10.389 & 10.140 & 68.120 & 1.958 & 4.286 & $2658.900^{* * *}$ & $34,193.000^{* * *}$ & -2.199 & -2.659 \\
\hline Japan & 27.500 & 11.036 & 14.000 & 91.450 & 2.615 & 8.389 & $7707.900^{* * *}$ & $28,416.000^{* * * *}$ & $-4.060^{* * *}$ & $-4.614^{* * *}$ \\
\hline Sweden & 21.936 & 10.280 & 9.300 & 77.920 & 1.766 & 3.933 & $2204.200^{* * *}$ & $31,653.000^{* * *}$ & $-3.258^{* *}$ & $-4.333^{* *}$ \\
\hline Russia & 40.052 & 24.668 & 15.420 & 200.495 & 3.121 & 12.520 & $15,436.000^{\text {**** }}$ & $29,892.700^{* * * *}$ & $-3.124^{* *}$ & $-3.412^{*}$ \\
\hline South Africa & 23.262 & 7.625 & 0.000 & 57.970 & 1.565 & 3.209 & $1584.300^{* * *}$ & $34,064.000^{* * * *}$ & -2.150 & -3.113 \\
\hline Germany & 24.383 & 9.872 & 12.170 & 83.230 & 2.124 & 5.869 & $4140.200^{* * *}$ & $29,841.500^{* * * *}$ & $-3.939^{* * *}$ & $-4.519^{* * *}$ \\
\hline Switzerland & 20.900 & 10.848 & 8.756 & 88.032 & 2.704 & 9.299 & $9126.800^{* * *}$ & $25,366.500^{* * *}$ & $-5.837^{* * *}$ & $-6.945^{* * *}$ \\
\hline
\end{tabular}

\begin{tabular}{|c|c|c|c|c|c|c|c|c|c|c|}
\hline Crude oil & 0.00001 & 0.049 & -0.440 & 0.425 & 0.88829 & 12.559 & $11,932.000^{* * *}$ & $90.992^{* * *}$ & $-26.929^{* * *}$ & $-26.930^{* * *}$ \\
\hline USA & -0.00021 & 0.071 & -1.046 & 1.062 & 0.40806 & 51.805 & $199,090.000^{* * * *}$ & $79.897^{* * *}$ & $-27.740^{* * * *}$ & $-27.733^{* * *}$ \\
\hline Canada & -0.00012 & 0.067 & -0.372 & 0.487 & 0.42034 & 3.315 & $867.490^{* * *}$ & $63.328^{* * *}$ & $-27.432^{* * * *}$ & $-27.425^{* * *}$ \\
\hline UK & -0.00040 & 0.069 & -0.365 & 0.372 & 0.31089 & 2.590 & $526.190^{* * *}$ & $37.654^{*}$ & $-26.814^{* * *}$ & $-26.807^{* * *}$ \\
\hline India & -0.00038 & 0.061 & -0.470 & 0.457 & 0.089124 & 9.876 & $7236.200^{* * *}$ & $79.206^{* * *}$ & $-26.966^{* * *}$ & $-26.959^{* * *}$ \\
\hline Mexico & -0.00038 & 0.050 & -0.452 & 0.492 & 0.41875 & 5.176 & $2038.900^{* * * *}$ & $29.593^{* * * *}$ & $-26.594^{* * * *}$ & $-26.595^{* * *}$ \\
\hline Japan & -0.00041 & 0.059 & -0.327 & 0.541 & 1.7984 & 13.239 & $13,959.000^{* * *}$ & $49.537^{* * *}$ & $-26.640^{* * * *}$ & $-26.635^{* * *}$ \\
\hline Sweden & -0.00024 & 0.071 & -0.333 & 0.358 & 0.35962 & 2.503 & $502.970^{* * * *}$ & $86.427^{* * *}$ & $-28.731^{* * * *}$ & $-28.723^{* * *}$ \\
\hline South Africa & -0.00021 & 0.031 & -0.346 & 0.393 & 0.77326 & 26.164 & $50,949.000^{* * * *}$ & $40.708^{* * * *}$ & $-27.049^{* * * *}$ & $-27.042^{* * * *}$ \\
\hline Germany & -0.00011 & 0.056 & -0.256 & 0.306 & 0.69931 & 2.838 & $742.600^{* * *}$ & $54.874^{* * *}$ & $-26.762^{* * *}$ & $-26.756^{* * *}$ \\
\hline Switzerland & -0.00032 & 0.099 & -0.822 & 0.457 & -0.9604 & 9.836 & $7448.300^{* * *}$ & $137.748^{* * *}$ & $-27.024^{* * *}$ & $-27.017^{* * *}$ \\
\hline
\end{tabular}

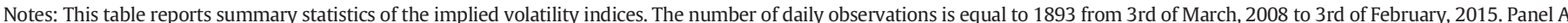
reports statistics for the levels, while Panel B reports results for log differences. ADF is the t-statistics for the Augmented Dickey-Fuller test.

*** Denotes significance at the $1 \%$ level.

** Denotes significance at the $5 \%$ level.

* Denotes significance at the $10 \%$ level.

levels of implied volatility of equities are similar and convey the same story. They are positively skewed, non-normal and exhibit high kurtosis. $^{21}$

The Lung-Box portmanteau statistics reported in Table 1 are computed for the last four weeks of the levels and the log changes of implied volatility. As can be seen in the table, all indices are highly serially correlated indicating the presence of temporal dependence in the implied volatility process and its log difference. As a response to the arrival of new information, the market adjusts the volatility prediction and consequently options prices. In this respect, implied volatility is similar to historical volatility which is characterized by clustering and serial correlations.

The results of the unit root test for the levels of the indices are reported in the last two columns of Table 1 . The null hypothesis of the ADF test is that there is a unit root in the variable. We tested two specifications of the implied volatility process to infer stationarity. As shown in the table, the implied volatility of equities are all stationary at the $5 \%$ level, while the implied volatilities processes of oil and the volatility of Mexican, Russian and South African equity may contain a unit root. However, when we tested the changes in log implied volatility indices, the null of non-stationarity was rejected at a $1 \%$ level in all markets as shown in Panel B of Table 1.

To get an idea on how oil implied volatility is related to equity implied volatilities, we computed the simple correlation coefficients. The correlation matrix is presented in Table 2. Panel A of the table reports correlations at the levels of the index, while Panel B reports correlations among log volatility's changes. At the price levels, the implied volatility of oil is highly correlated with equity volatility in all equity markets. The correlation between oil and equity volatility is greater than 0.72 in all

\footnotetext{
21 The same applies to the distributional properties of the log volatility changes reported in Panel B of Table 1. Compared to the levels, these exhibit lower positive skewness and higher kurtosis.
}

markets. This indicates that equity options are priced with volatilities that are not independent from the uncertainty in the oil market. Similarly, the level of association among equity markets' volatilities, which is even higher and reflects the high extent to which volatilities used to price options, is related across equity markets.

The highest correlations are with the US. The simple correlation coefficient between the US implied volatility and other equity markets' implied volatility is not less than 0.81 . This correlation is more pronounced among European and North American equities than with other equity markets. For instance, the correlation between the US and European equity volatilities is not less than 0.92 and it reaches 0.98 with the UK. This reflects the level of equity market integration and volatility association between the US and Europe.

Panel B reports the correlation matrix for the log volatility changes. In the panel, the correlation between oil and equity daily implied volatility changes is average and significantly lower than the association in levels. The correlations between changes in oil volatility and changes in the volatility of the US, UK, Germany, and Canada are 0.29, 0.30, 0.34 and 0.28 respectively. The high association in the levels of oil-equity implied volatilities and the relatively lower correlation of changes show that, in general, the levels of uncertainty in equity markets are associated with the levels of uncertainty in the oil market. However, the daily changes in equity implied volatilities may not be closely related to the daily dynamics of oil volatility which may be driven by other factors.

It is worth to mention here that changes in implied volatility remain high among equity markets in Europe and North America. For instance, the correlations between changes in US implied volatility and changes in the implied volatilities of the UK, Canada, Sweden, and Germany are $0.70,0.72,0.61$ and 0.76 respectively. Similarly Panel B reports high pairwise correlations among changes in the volatility in any two European countries. For example, the changes in implied volatility of German equities are highly correlated with the changes in Canada, the 
Table 2

Unconditional correlation among the implied volatility indices (crude oil and stock markets).

\begin{tabular}{|c|c|c|c|c|c|c|c|c|c|c|c|c|}
\hline & Crude oil & USA & Canada & UK & India & Mexico & Japan & Sweden & Russia & South Africa & Germany & Switzerland \\
\hline \multicolumn{13}{|l|}{ Panel A: Levels } \\
\hline Crude oil & 1.000 & & & & & & & & & & & \\
\hline USA & 0.852 & 1.000 & & & & & & & & & & \\
\hline Canada & 0.801 & 0.961 & 1.000 & & & & & & & & & \\
\hline UK & 0.815 & 0.981 & 0.963 & 1.000 & & & & & & & & \\
\hline India & 0.721 & 0.819 & 0.728 & 0.806 & 1.000 & & & & & & & \\
\hline Mexico & 0.855 & 0.907 & 0.814 & 0.888 & 0.872 & 1.000 & & & & & & \\
\hline Japan & 0.719 & 0.846 & 0.793 & 0.854 & 0.749 & 0.853 & 1.000 & & & & & \\
\hline Sweden & 0.825 & 0.975 & 0.955 & 0.975 & 0.825 & 0.891 & 0.819 & 1.000 & & & & \\
\hline Russia & 0.771 & 0.860 & 0.811 & 0.833 & 0.727 & 0.809 & 0.787 & 0.825 & 1.000 & & & \\
\hline South Africa & 0.859 & 0.930 & 0.889 & 0.928 & 0.831 & 0.915 & 0.837 & 0.929 & 0.791 & 1.000 & & \\
\hline Germany & 0.819 & 0.966 & 0.971 & 0.960 & 0.772 & 0.847 & 0.820 & 0.957 & 0.854 & 0.882 & 1.000 & \\
\hline Switzerland & 0.785 & 0.921 & 0.896 & 0.933 & 0.765 & 0.863 & 0.871 & 0.910 & 0.825 & 0.869 & 0.906 & 1.000 \\
\hline
\end{tabular}

Panel B: Log volatility changes

Crude oil $\quad 1.000$

USA $\quad 0.297$

Canada $\quad 0.286$

UK $\quad 0.304$

India $\quad 0.135$

Mexico $\quad 0.228$

Japan $\quad 0.133$

Sweden $\quad 0.238$

Russia $\quad 0.228$

South Africa $\quad 0.183$

Germany $\quad 0.343$

Switzerland $\quad 0.226$

$\begin{array}{ll}1.000 & \\ 0.697 & 1.000 \\ 0.726 & 0.720 \\ 0.218 & 0.208 \\ 0.291 & 0.283 \\ 0.253 & 0.241 \\ 0.612 & 0.626 \\ 0.324 & 0.340 \\ 0.300 & 0.340 \\ 0.759 & 0.802 \\ 0.473 & 0.483\end{array}$

$\begin{array}{lll}1.000 & & \\ 0.208 & 1.000 & \\ 0.297 & 0.071 & 1.000 \\ 0.263 & 0.198 & 0.103 \\ 0.630 & 0.215 & 0.250 \\ 0.348 & 0.209 & 0.142 \\ 0.357 & 0.167 & 0.146 \\ 0.790 & 0.237 & 0.324 \\ 0.505 & 0.184 & 0.209\end{array}$

1.000

0.225

0.223

0.229

0.298

0.210

1.000
0.342
0.291
0.714
0.436

1.000

0.226

0.379

0.269

1.000
0.382
0.241

1.000

0.543

1.000

UK and Sweden. At the same time, they are weakly correlated with either the crude oil or the other equity markets outside the US or Europe.

\section{Empirical results}

\subsection{Static volatility connectedness analysis}

The matrix presented in Table 3 reports the full sample cross market connectedness of the first difference of implied volatilities. ${ }^{22}$ The diagonal elements of the matrix represent the own market connectedness and are not particularly interesting in our context. The off diagonal elements (i.e. $\left.C_{i \leftarrow j}(H)\right)$ of the matrix measure the pairwise volatility directional connections and are particularly important for our study. Most importantly is the first column which measures the directional connectedness from the crude to US equities (i.e. $C_{j \leftarrow \text { oil }}(H)$ ). Similarly, the first row of the table is important as it measures the directional connectedness into the oil market from other equity markets (i.e. $C_{o i l \leftarrow i}(H)$ ).

For instance, the highest oil volatility connectedness of around $29 \%$ is observed from oil to Canada (See first column, third row). In return the connectedness from Canada to oil is almost nil (See third column, first row). The difference between the two pairwise connectedness measures implies that the net pairwise connectedness is from oil volatility to the volatility of Canadian equities. This is expected as oil is an important factor that is weighted heavily by Canadian stock investors. ${ }^{23}$

The second and third highest oil volatility connectedness is observed in the US and UK markets where oil's contribution amounts to $18.4 \%$ and $19.5 \%$ for the two markets respectively. However, the two markets contribute to oil volatility with a rate of $2 \%$ only. Hence, the net pairwise connectedness is from oil to the US and UK equities. Similar patterns of oil equity market connectedness are observed with the rest of markets. One factor behind the relatively higher pairwise directional

\footnotetext{
22 All the results in the table are based on vector autoregression of order 2 , and generalized variance decompositions of 10-day ahead forecast errors. We also use Choleskyfactorizations with alternative orderings. The results (are not reported but available from the authors upon request) remain qualitatively similar.

${ }^{23}$ For instance, the drop in oil prices following the mid of 2014 led to more than $20 \%$ drop in the value of Canadian equities.
}

connectedness with Canada, the UK and the US is that the three economies are among the top oil producers in the world. ${ }^{24}$

Russia is a big producer of oil. But the risk transfer from oil to Russian equities is not found to be as strong as in oil producing countries (Canada, the US and the UK). On the other hand, Germany is not an oil producer but with a high connectedness that is almost equal to the UK's. Therefore, the level of connectedness can not be strictly explained by being an oil producer. Another possible explanation lies in the high presence of oil option and equity traders in the group of high connected countries. These traders are active in both the oil and equity markets and hence their presence creates common volatility linkages. ${ }^{25}$

However, the dynamic rolling estimation of risk transfer from oil to Russian equities shows significant risk transfer in the sample that spans over the period 2010-2013 (See Fig. 3). As the sample moves out to 2014, the risk transmission to Russian equities fades. This can be explained by the sanctions that were imposed on the Russian economy in February 2014 upon the annexation of Crimea and the Ukraine crisis. While the nature of the impact of oil on Russian stocks is known, the impact of these sanctions is ambiguous. Hence, we may conclude that after 2014, the volatility of Russian equities was more driven by sanctions news rather than oil volatility. ${ }^{26}$

It is worth to mention here that while the return transmission from oil and equities can have a positive or a negative impact, ${ }^{27}$ the risk transfer has always a negative influence as it increases uncertainty in the receiving markets. For instance, the volatility transmission from oil to equities in oil producing countries creates uncertainties regarding the future prospects of oil and oil related companies. It also casts uncertainties on the future performance of banks that are exposed to the oil and gas sector. Particularly, in cases where government spending

\footnotetext{
24 The US is number 1, Canada is number 5 and the UK is number 23. For more information see http://www.eia.gov/beta/international/rankings/\#?prodact=53-1\&cy=2014

${ }^{25}$ This point has been brought to our attention by one of the referees.

${ }^{26}$ The Moscow stock exchange shows resilience during this period. There is an increase in volatility and a drop in prices before one stage of sanctions is implemented, but then the market rebounds to recoup losses afterwards.

27 In general it is positive in net oil exporter countries and negative in net oil importer countries. The nature of the impact is also sectoral. In general, a decrease in oil prices benefits airline and transportation, manufactures, household, water and utilities; but it harms the oil and gas sectors.
} 
Table 3

Full sample directional of implied volatility connectedness.

\begin{tabular}{|c|c|c|c|c|c|c|c|c|c|c|c|c|c|}
\hline \multirow[b]{2}{*}{ To market $i$} & \multicolumn{13}{|c|}{ From market $j$} \\
\hline & $\begin{array}{l}\text { Crude } \\
\text { oil }\end{array}$ & USA & Canada & UK & India & Mexico & Japan & Sweden & Russia & $\begin{array}{l}\text { South } \\
\text { Africa }\end{array}$ & Germany & Switzerland & Connectedness from others \\
\hline Crude oil & 94.4 & 0.2 & 0.0 & 0.2 & 0.3 & 1.9 & 0.2 & 0.1 & 1.4 & 0.7 & 0.6 & 0.0 & 6 \\
\hline USA & 18.4 & 71.7 & 0.1 & 2.0 & 0.0 & 3.4 & 0.3 & 1.4 & 1.3 & 0.1 & 0.8 & 0.5 & 28 \\
\hline Canada & 26.9 & 55.3 & 18.0 & 3.8 & 0.3 & 1.7 & 0.4 & 1.6 & 0.6 & 0.4 & 0.4 & 0.6 & 92 \\
\hline UK & 19.5 & 57.1 & 2.1 & 17.3 & 0.0 & 3.1 & 0.1 & 2.5 & 0.8 & 0.2 & 1.3 & 0.1 & 87 \\
\hline India & 3.9 & 8.2 & 0.1 & 0.5 & 82.3 & 3.5 & 0.1 & 0.6 & 0.2 & 0.2 & 0.1 & 0.1 & 18 \\
\hline Mexico & 11.3 & 13.5 & 1.1 & 2.4 & 0.5 & 66.6 & 0.3 & 0.6 & 1.9 & 0.1 & 1.6 & 0.2 & 33 \\
\hline Japan & 0.9 & 27.1 & 0.3 & 4.5 & 0.1 & 3.8 & 54.0 & 0.1 & 0.7 & 0.3 & 0.2 & 0.2 & 46 \\
\hline Sweden & 14.4 & 47.6 & 1.8 & 5.7 & 0.3 & 4.1 & 0.5 & 23.2 & 0.6 & 0.4 & 0.5 & 0.7 & 77 \\
\hline Russia & 8.0 & 22.5 & 0.3 & 1.8 & 0.4 & 0.8 & 0.1 & 1.3 & 64.5 & 0.0 & 0.3 & 0.0 & 35 \\
\hline South Africa & 11.6 & 23.3 & 1.1 & 7.4 & 0.5 & 3.1 & 0.2 & 0.8 & 0.5 & 50.5 & 1.2 & 0.0 & 50 \\
\hline Germany & 18.1 & 53.0 & 5.6 & 4.4 & 0.0 & 3.1 & 0.3 & 3.5 & 1.2 & 0.0 & 10.0 & 0.8 & 90 \\
\hline Switzerland & 12.4 & 36.9 & 2.2 & 8.2 & 0.1 & 2.5 & 2.1 & 3.1 & 2.0 & 0.1 & 1.8 & 28.7 & 71 \\
\hline Connectedness to others & 139 & 345 & 15 & 41 & 3 & 31 & 5 & 16 & 11 & 3.0 & 9.0 & 3.0 & 619 \\
\hline Connectedness including own & 248 & 416 & 33 & 58 & 85 & 98 & 59 & 39 & 76 & 53 & 19 & 32 & Total connectedness $=51.60 \%$ \\
\hline
\end{tabular}

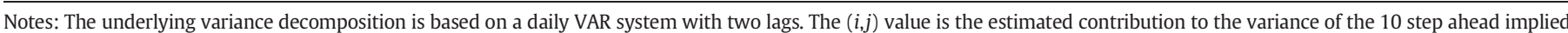

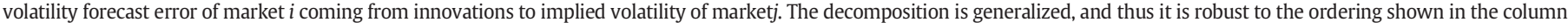

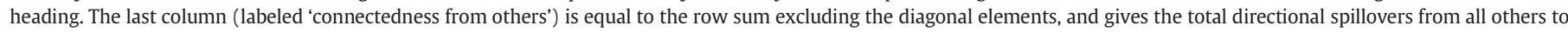

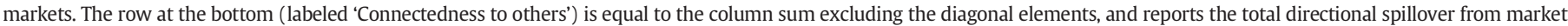

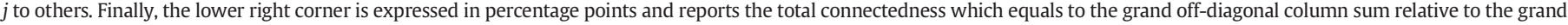
column sum including diagonals.

depends on oil, there are also uncertainties regarding future public spending and economic activity.

The oil cross country directional connectedness shows that pairwise connectedness of oil is greater with North American and Western European countries that have well developed and mature equity markets. For instance, the connectedness measure observed from oil to Germany and Switzerland is $18.1 \%$ and $12.4 \%$ respectively, whereas it is $3.9 \%$, $11.3 \%, 8 \%, 11.6 \%$ for India, Mexico, Russia and South Africa respectively.

There are many theoretical channels of information transmission from oil volatility to equity volatility. For instance, high volatility in the oil market can be translated into higher earnings volatility in oil and oil related companies. Oil price volatility may create comparable uncertainties regarding business cost, disposable income and consumer spending on energy using durable goods. Volatile oil markets may also convey information on future global economic uncertainty and, hence, they can influence the volatility in global equity markets. Therefore, we expect high transmissions from oil volatility to equity volatility. ${ }^{28}$

The row sum of the pairwise connectedness measures the aggregate contribution of all others to each of the twelve markets in the study (the total directional connectedness). In other words, the contribution from others in the last column of the matrix is the sum of the volatility transmission from all markets to a particular market. Similarly, the column sum of all pairwise connectedness measures the total directional connectedness to others from the corresponding market. This means that the contribution to others is the sum of pairwise directional transmission of implied volatility from a particular market to all other markets. ${ }^{29}$ The oil implied volatility contribution to the equity volatility of all markets in the system amounts to $139 \%$ while oil volatility only receives a $6 \%$ contribution from others. In that sense, oil is regarded as a transmitter of shocks to equities.

In the system of countries that we have, the US and the oil markets are the only two markets of the twelve markets under study in which the contribution to others' connectedness is higher than the contribution from others connectedness. The positive net connectedness of the oil market with all other markets is $133 \%$, indicating that it is a net transmitter of

\footnotetext{
28 If US equity reflects the health of the global economy and the future demand for oil, then transmissions from equity to oil should be expected as well. However, these transmissions are less direct than the direct spillover of oil volatility on corporate earnings and returns.

${ }^{29}$ Note that the contribution to others' forecast error variance is not constrained and it may exceed $100 \%$.
}

volatility shocks to others. The US market is also a net transmitter to all others and its net contribution is two and a half folds the net contribution of oil at around $317 \%$. The net connectedness of the rest of markets is negative, which indicates that they are net recipients of volatility shocks from other markets. Among the markets that have negative net total connectedness, Germany has the highest value at $-81 \%$, followed by Canada at $-77 \%$, Switzerland at $-68 \%$, South Africa at $-47 \%$ and the UK at $-46 \%$.

The total connectedness of implied volatilities that is reported in the lower right corner of the table is $52 \%$. This is relatively high compared to the same measure computed for volatility connectedness among the same markets using range based historical volatility estimators instead of implied volatilities from option prices. For instance, it is higher than the total volatility spillover computed by Diebold and Yilmaz (2009) for the same markets. ${ }^{30}$ Given that the period of the study contains several stress periods such as the financial crisis in 2008, the European sovereign debt crisis following the Greek crisis in late 2009 and early 2010 the US fiscal cliff and the oil price collapse, there is a high degree of connectedness in the sample. ${ }^{31}$ There is another reason why the total connectedness of implied volatilities is higher than historical or range based volatilities. The connectedness of implied volatilities measures fear connectedness in addition to volatility association. In volatile markets, options are priced with higher volatilities than the expected volatility. ${ }^{32}$ Hence, the implied volatility association not only reflects volatility crossovers but also the fear premium transmissions among markets.

\subsection{Dynamic volatility connectedness analysis}

The static connectedness analysis provides a good characterization of the connectedness of implied volatilities over the full sample period. However, it is not helpful in understanding how connectedness changes over time. In order to get a better understanding, we estimate the vector autoregression using 200 days rolling window,

\footnotetext{
30 In the study of Diebold and Yilmaz (2009), the total connectedness is found to be $39.5 \%$. The markets in their sample are different, but still we share the following countries with them: the US, the UK, Germany, India and Mexico.

31 The fiscal cliff refers to the Republican-Democratic disagreement regarding spending cuts towards the end of 2012. The failure to reach a compromise by the two parties unnerved the US financial markets.

${ }^{32}$ In this sense the implied volatility used to price options can be considered as a composite measure of volatility that reflects both the expected future volatility and the uncertainty around that expected volatility or alternatively the fear premium.
} 
(a) Crude oil to All

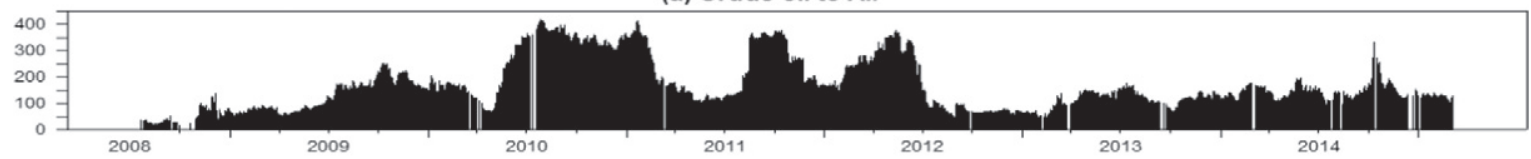

(b) All to Crude oil

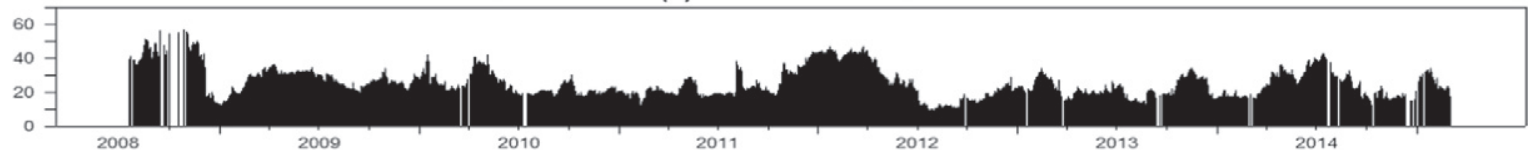

(c) Net Crude oil

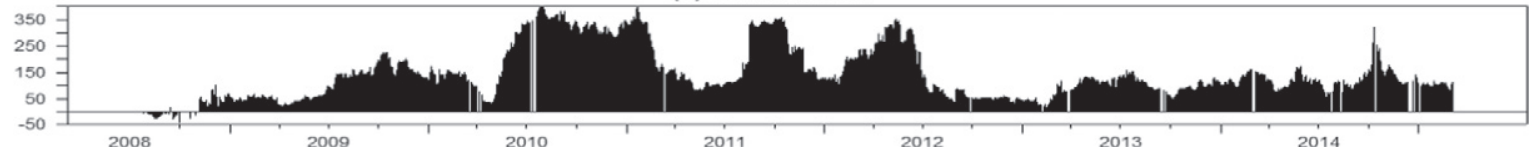

Notes: This figure shows the directional volatility connectedness from oil to all markets over the sample period of $3^{\text {rd }}$ of March, 2008 to $3^{\text {rd }}$ of February, 2015 estimated with a rolling window of 200-day. The predictive horizon of the underlying variance decomposition is 10-days ahead.

Fig. 2. Directional implied volatility connectedness.

and then assess the extent and nature of connectedness over time using the corresponding time series of the total directional connectedness measure. ${ }^{33}$ Fig. 2, Panel (a) presents plots of total directional connectedness of implied volatility originating from the oil market and transmitting to other equity markets (i.e. $C_{\mathbf{m}} \leftarrow$ oil $(H)$ ). Panel (b) of the same graph presents the transmissions of implied volatility in the opposite direction (i.e. from all equity markets to the oil market) (i.e. $C_{o i l \leftarrow}(H)$ ). The net transmissions are presented in Panel (c) (i.e. $C_{i}(H)$ ).

The figure shows that the connectedness is largely dominated by the information transmission from the crude oil market to other equity markets and not the other way around. This is clear from the order of magnitude of the information spills in Panels (a) and (c) in the Figure. The crude oil transmits to the rest of equity markets in the order of $100 \mathrm{~s}$ while it receives in the order of $10 \mathrm{~s}$. Hence, there is a positive net transmission of information from the oil market to other equity markets. The graph of the net transmissions is presented in Panel (c) and it shows clearly that, for most of the sample period, the directional connectedness is established more by the transmissions from the oil market to other markets. The only exception occurred at the start of the sample (in 2008) when the directional connectedness with oil was more related to transmissions from equities. This can be explained by the financial crisis that started in the US and rippled across the global equity, asset and commodity markets in $2008 .^{34}$ The US market during that period has dominated the information transmission across global markets including the oil market. ${ }^{35}$ This result is consistent with the empirical evidence of Diebold and Yilmaz (2012) who found that volatility transmissions from the equity market to the commodity market intensify during periods of stress.

Fig. 2 also shows that the directional connectedness is time varying. Three cycles of connectedness can be spotted in the graph. The first corresponds to the beginning of the sample and extends from the first quarter of 2008 to the first quarter of 2009. The second cycle corresponds to the period of recovery in the global economy which extends from the second quarter of 2009 to mid 2012. Finally, the third cycle represents the period that covers the mid of 2012 to the end of the sample in 2015.

In the first cycle, the directional connectedness between oil and equity is low, especially from the direction of the oil market to equity markets. It

\footnotetext{
33 We also used various lags in the VAR models to check the sensitivity to the number of lags. We found that our results are robust to lag selection.

${ }^{34}$ As we will see in the analysis of pairwise directional connectedness, we have also found a dominant role of the US equity at the start of the sample.

35 At the price levels, both the crude oil and the S\&P500 had crashed in the wake of the Lehman Brothers collapse in September 2008. The price of oil dropped from $\$ 140$ to around $\$ 39$, while the stock index decreased from 1600 to 400 points in the same period.
}

is only during the financial meltdown (in September 2008) that transmissions from equities to oil intensified and, hence, the connectedness during that period was dominated by equities. The second cycle witnessed an increased transmission from oil to equities with no significant changes in the information flow in the opposite direction. The directional connectedness in the second cycle is dominated by the oil market volatility. A possible explanation is that the influence of uncertainty in the oil market is higher during initial growth stages as it may threaten the recovery of the global economy and, consequently, equity markets. Therefore, oil uncertainty is closely watched by all markets. Its influence is less important in the relatively stable macroeconomic environment that prevailed during the last cycle. This is because the connectedness decreased though it was still dominated by oil to a much lower extent.

To further focus on the association between oil and individual equity markets, we computed the net pairwise directional connectedness of oil with each of the markets included in the study. Fig. 3 presents the plots of net pairwise directional dynamic connectedness of oil volatility with the volatility of each of the equity markets over the sample period. As can be seen in the figure, the net pairwise transmissions from the oil market to equities are positive. This indicates that risk transfer between the oil market and the other equity markets is asymmetric and dominated by the transmissions from the oil market. The result is uniformly valid across all the equity markets included in the sample. Therefore, we may conclude that oil is the important market in establishing the association with other equity markets. Finally, notice that the pairwise analysis of connectedness repeats the same patterns that was observed before. For instance, the pairwise connectedness in 2008 was dominated by equities particularly in the oil producing countries such as USA, UK, and Canada. ${ }^{36}$ Similarly, the figure shows that the connectedness is weak at the beginning of the sample or over the period from the first quarter of 2008 to the mid of 2009 and that it increased with the connectedness dominated by the oil market from the mid of 2009 to the mid of 2012. The connectedness then decreased as we approached the end of the sample with the net pairwise directional connectedness were still dominated by oil but to a lower extent.

\section{Robustness of results}

This section checks whether results in Sections 5 are robust to the choice of the volatility measure. This section also uses Granger

${ }^{36}$ Although Russia is a big producer of oil, the connectedness of its equity to oil is less pronounced in the figure. 


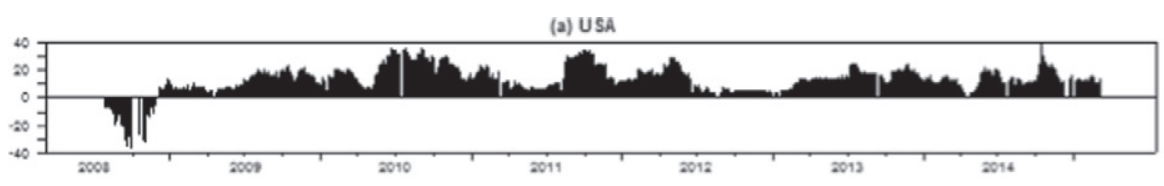

(b) Canada

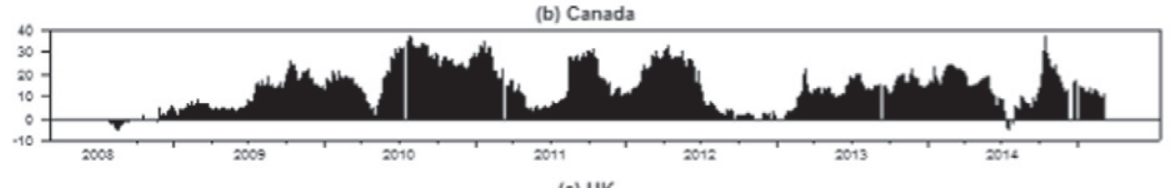

(c) Ux

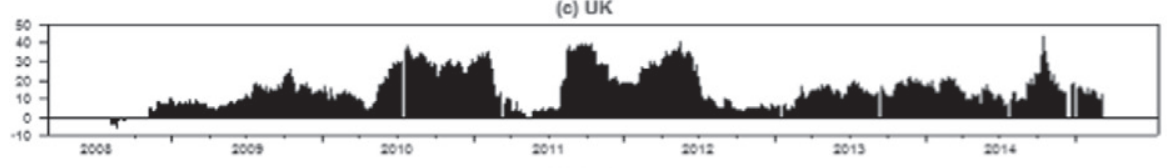

(d) India
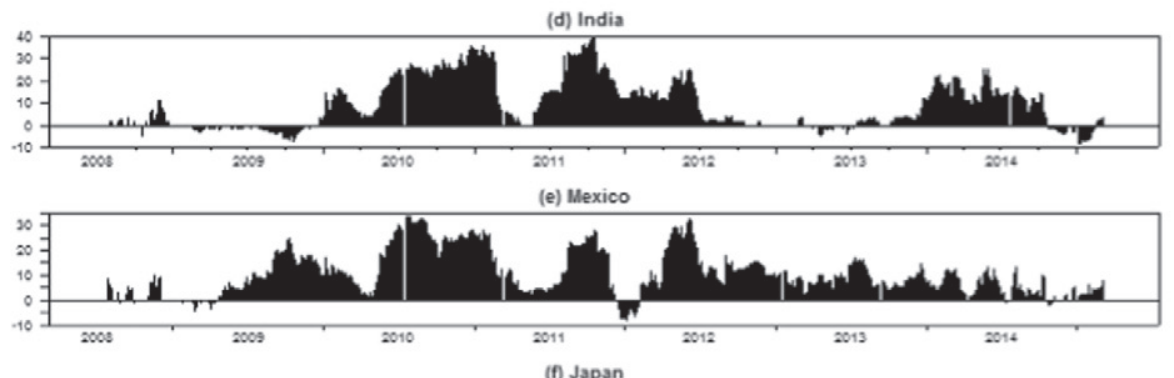

(f) Japan
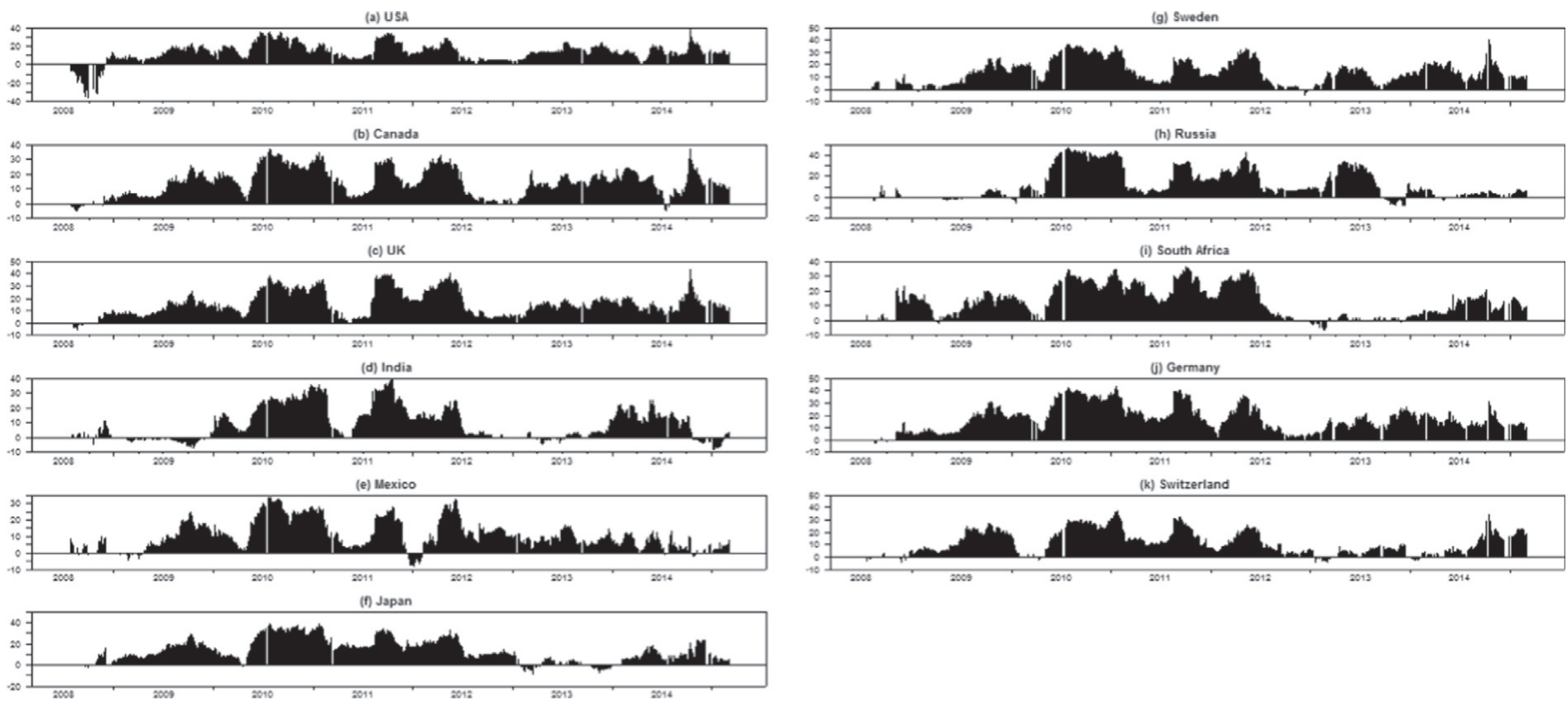

(h) Russia

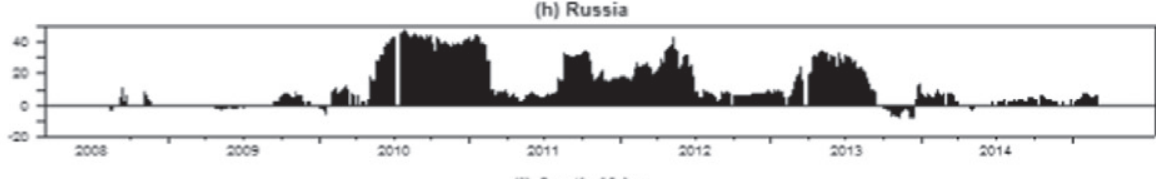

South Africa

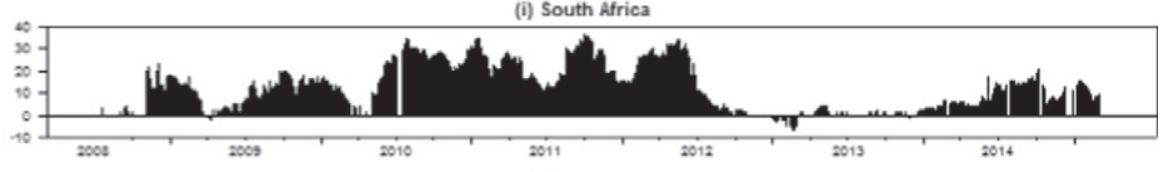

(i) Germany

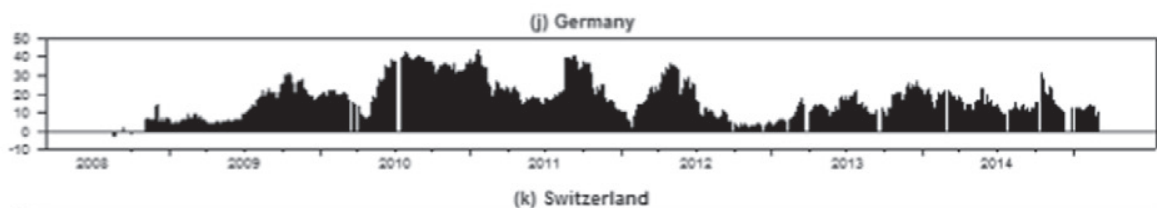

(k) Switzerland

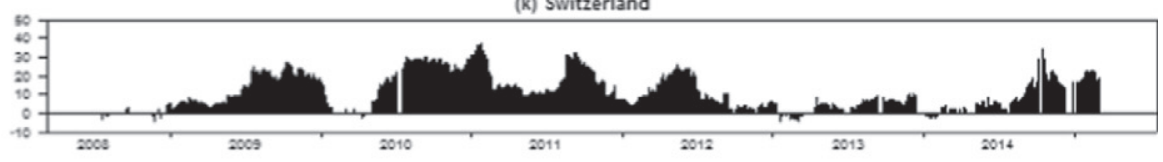

2013

Notes: This figure shows the net pairwise directional connectedness from oil to each market over the sample period of $3^{\text {rd }}$ of March, 2008 to $3^{\text {rd }}$ of February, 2015 estimated with a rolling window of 200- day. The predictive horizon of the underlying variance decomposition is 10-day ahead. Positive (negative) values indicate that oil is a net transmitter (receiver) of shocks to the respective market. 
causality tests to investigate the short run lead-lag relationship between oil and equity volatilities.

\subsection{Alternative volatility measures}

To check robustness to the latent variance measure, we use two alternative volatility estimates that are widely used in the literature: these are the squared returns and the conditional volatility based on a GARCH model.

First, we use daily squared returns to proxy the latent volatility process. ${ }^{37}$ To construct the equity return series of the equity markets, we compiled the Morgan Stanley Capital international (MSCI) stock market indexes for the relevant countries from Thomson Reuters DataStream. These indexes are capital weighted and float adjusted. They include all companies traded in each equity market. For each of the index series, we computed daily continuously compounded returns as the change in log prices. The squared returns of the markets are computed across the same sample length which covers the period from the 3rd of March 2008 to the 3rd of February 2015.

Table 4, Panel A reports the matrix of markets' spillovers. The panel shows similar and different transmission patterns as those reported in Section 5. As shown in the table, the oil market is a net transmitter of volatility to all markets in the system. The total transmission of shocks in the system is around 55\% which is comparable to the total spillover index computed previously. These results conform nicely with the analysis in Section 5. However, the table also shows that the connectedness of the oil market with the group of oil producing countries is less pronounced than that reported using implied volatilities in Table 3. For instance, the pairwise connectedness of oil is higher in Germany and Switzerland (16.1\% and $15.3 \%)$ than in either the US $(13.2 \%)$ or in Canada (14.7\%). The highest connection is with the UK where oil spills $17.2 \%$ on UK equities. As previously stated, the connectedness of Russia, a big oil producer, remains relatively low when compared to either the rest of oil producing countries (UK,US and Canada) or to other countries (Germany, Switzerland, Mexico).

The inference from realized volatilities is also less revealing in terms of the difference between developed and developing equity market linkages. As mentioned previously, the analysis based on implied volatility reveals a clear distinction between transmissions from oil to developed markets' equities and to other equities where transmissions are found to be higher in developed markets (see Table 3). However, when we change the latent volatility measure to squared returns, this distinction disappears and the oil risk transfer follows similar patterns across all developed and developing equity markets.

It is well known that squared returns represent a noisy measure of volatility. Therefore, we use another measure of volatility implied from a GARCH-based model. In particular, we estimated an AR(1)$\operatorname{GARCH}(1,1)$ model for each of the return series. This new conditional volatility measure is then used to analyze volatility spillovers.

Panel B of Table 4 reports the results that are based on GARCH volatilities. As can be seen in the table, there isn't much change in the results as compared to Panel A. The GARCH volatilities of oil are still at the center of transmissions in the system. Oil has remained the net transmitter of shocks to all equity markets. Similar to squared returns, the GARCH measure is less able to distinguish between oil and non-oil producing countries. The new volatility measure is also less revealing in terms of distinguishing between developed and developing countries and, therefore, we may conclude that implied volatilities provide more information of the nature of oil equity relationship.

Finally, Panels (a) and (b) in the Fig. 4 present the plots of net pairwise directional dynamic connectedness of oil volatility with the volatility of each of the equity markets over the sample period using the two alternative volatility measures. The figure shows that the

\footnotetext{
37 On using squared returns to measure volatility See Foster and Nelson (1996) and Triacca (2007).
}

connectedness is largely dominated by the information transmission from the crude oil market to other equity markets and not the other way around. These findings are largely consistent with the previous results obtained from the implied volatility measures. ${ }^{38}$

To further investigate the association between oil and equities, we also test for causality between the oil implied volatility index and the other implied volatility indexes. The tests complement the previous analysis in which no formal testing for the results was conducted. Moreover, the test checks if the association between oil and equity volatilities can stand a change in the model from which inference is taken.

\subsection{Granger causality tests}

The analysis in the previous section stresses the importance of oil transmissions in the directional connectedness between oil and implied volatilities. In this section we investigate risk transfer from oil to equity using Granger causality tests.

The tests are employed to investigate lead (lag) transmission of volatility from oil to equities and vice versa. A significant risk transfer from oil to equity and an insignificant transmission in the opposite direction confirm the previously observed patterns.

Table 5 reports the results of the tests for the log differences in the volatility indices. ${ }^{39}$ The appropriate number of lags in the analysis was chosen based on the Schwartz information criteria and the Lutkepohl's likelihood ratio test. Table 5 shows that the lagged changes in oil implied volatility is informative of the future changes in equity volatility in all markets. The causality in the other direction is insignificant at conventional levels. ${ }^{40}$ This can be explained by the sensitivity of equity implied volatility indices to macroeconomic fundamentals where oil is a significant contributor. The uncertainty changes in the oil market may have their implications on the expected macroeconomic environment and capital market expectations and, hence, they can easily transmit to equities. Thus, we may conclude that oil plays an important role in the directional connectedness between oil volatility and equity volatility during the sample period. ${ }^{41}$

It is worth to mention here that the causality in volatility is sometimes not independent of the corresponding return causalities. With more market openness, the flow of information from one market to another intensifies and thus affects both returns and volatilities. These patterns can be seen clearly during market stress. For instance, the recent plunge in oil prices to \$27.62 in January 2016 has dragged down the S\&P500 index by $9 \%$. This simultaneous drastic drop in oil and equity prices also reflects the association of volatilities between the two markets.

\section{Conclusion}

The previous studies have concentrated on the impact of oil price changes on equity price changes, and on using ARCH or realized volatilities to measure the latent volatility process. Moreover, the causality between oil volatility and equity volatility was largely derived from static models that cover the whole sample period. Instead, in this paper, we exploit newly introduced implied volatility indices and new directional connectedness measures to study the risk transfer between the oil

\footnotetext{
38 We also conduct the net pairwise directional dynamic connectedness of oil volatility with the volatility of each of the equity markets over the sample period. The plots show a similar pattern to those shown in Fig. 3. To conserve space, the plots are not reported in the paper but they are available from the authors upon request.

39 We also conduct the Granger causality test using the levels of volatility indexes. Results are qualitatively similar and therefore are not reported. They are available from the authors upon request.

${ }^{40}$ The only exception is the US market where the change in equity volatility (the VIX) is also predictive of changes in oil volatility. The VIX is a benchmark that is closely watched by all markets especially after the global crisis in 2008 .

41 The results are robust to the choice of lags in the Granger causality tests. The results for various lags are not reported but they are available from the authors upon request.
} 
Table 4

Directional connectedness using alternative volatility measures.

\begin{tabular}{|c|c|c|c|c|c|c|c|c|c|c|c|c|c|}
\hline \multirow[t]{2}{*}{ To market $i$} & \multicolumn{13}{|c|}{ From market $j$} \\
\hline & Crude oil & USA & Canada & UK & India & Mexico & Japan & Sweden & Russia & $\begin{array}{l}\text { South } \\
\text { Africa }\end{array}$ & Germany & Switzerland & Connectedness from others \\
\hline \multicolumn{14}{|l|}{ Panel A: Realized volatility } \\
\hline Crude oil & 86.6 & 2.5 & 3.5 & 1.3 & 0.8 & 1.7 & 0.8 & 1 & 0.4 & 0.4 & 0.4 & 0.6 & 13 \\
\hline USA & 13.2 & 69.8 & 12 & 0.7 & 2.7 & 1.5 & 2.3 & 1.2 & 1.1 & 2.8 & 0.2 & 2.6 & 40 \\
\hline Canada & 14.7 & 31.9 & 50.2 & 0.7 & 4 & 2.3 & 1.4 & 0.5 & 1 & 1.7 & 0.8 & 0.7 & 60 \\
\hline UK & 17.2 & 21.4 & 20.7 & 38.7 & 2.7 & 2.1 & 1.7 & 0.8 & 0.1 & 1.1 & 2.4 & 1.3 & 72 \\
\hline India & 12.1 & 2.5 & 3 & 4 & 84.2 & 2 & 0.5 & 0.2 & 0.2 & 0.3 & 0.8 & 0.1 & 26 \\
\hline Mexico & 13.7 & 31 & 14.7 & 10.3 & 2.8 & 27.5 & 1.1 & 1.5 & 3.7 & 1.7 & 0.5 & 1.5 & 83 \\
\hline Japan & 2.7 & 12.2 & 10 & 4.5 & 2.2 & 1.3 & 57.9 & 2.9 & 0.2 & 0.9 & 3.4 & 1.8 & 42 \\
\hline Sweden & 8.5 & 18 & 14.1 & 23.2 & 2.1 & 1.3 & 0.9 & 29.1 & 0 & 0.9 & 0.5 & 1.3 & 71 \\
\hline Russia & 9.1 & 10.3 & 13.1 & 12.4 & 2.7 & 3.9 & 0.4 & 1.7 & 49.4 & 1.3 & 1.8 & 1 & 58 \\
\hline South Africa & 10 & 13.5 & 18.5 & 12.6 & 2.5 & 1.7 & 4.7 & 2.3 & 3 & 35.4 & 0.9 & 1 & 71 \\
\hline Germany & 16.1 & 25.6 & 10.1 & 19.9 & 2.7 & 2.7 & 1.9 & 6.9 & 1.4 & 1.5 & 19.4 & 1.8 & 91 \\
\hline Switzerland & 15.3 & 21.4 & 14 & 24.3 & 2.5 & 2 & 1.9 & 3.1 & 0.5 & 0.9 & 4.9 & 19.3 & 91 \\
\hline Connectedness to others & 139 & 190 & 134 & 114 & 28 & 23 & 18 & 22 & 12 & 14 & 16 & 14 & 716 \\
\hline Connectedness incl. own & 248 & 416 & 33 & 58 & 85 & 98 & 59 & 39 & 76 & 53 & 19 & 32 & Total Connectedness $=54.88 \%$ \\
\hline \multicolumn{14}{|c|}{ Panel B: Conditional volatility } \\
\hline Crude oil & 86.9 & 2.3 & 4.4 & 3.5 & 0 & 0.1 & 0.3 & 0.2 & 0.2 & 0.5 & 0.2 & 1.5 & 13 \\
\hline USA & 12 & 79.8 & 4.2 & 3.9 & 0.7 & 0.1 & 0.7 & 0.3 & 5.9 & 1.9 & 0.2 & 0.6 & 31 \\
\hline Canada & 12.3 & 47 & 41.5 & 0.7 & 1.7 & 1.2 & 0.1 & 0.2 & 2.7 & 1.2 & 0.8 & 0.5 & 68 \\
\hline UK & 19.6 & 44.1 & 7 & 31 & 0.7 & 1 & 0.3 & 0.5 & 3.4 & 0.4 & 1.4 & 0.5 & 79 \\
\hline India & 10.4 & 0.8 & 0 & 4.9 & 86.2 & 5.6 & 0.1 & 0.1 & 0.1 & 0 & 1.7 & 0.2 & 24 \\
\hline Mexico & 14 & 33.8 & 3.1 & 17.4 & 0.8 & 30.7 & 0.1 & 0.4 & 7.2 & 0.9 & 0.6 & 0.8 & 79 \\
\hline Japan & 15.7 & 9.1 & 1 & 8.5 & 0.1 & 4.6 & 64.8 & 3.6 & 0.7 & 1.1 & 0.2 & 0.7 & 45 \\
\hline Sweden & 10.1 & 32.6 & 7.1 & 20.3 & 0.6 & 0 & 0.2 & 26.1 & 0.2 & 2 & 0.7 & 0.1 & 74 \\
\hline Russia & 8.2 & 12.4 & 2.9 & 13.7 & 1.2 & 1.8 & 0 & 0.4 & 61.2 & 0.1 & 0.1 & 2.1 & 43 \\
\hline South Africa & 8.2 & 35.4 & 6.5 & 17.3 & 1.9 & 3.5 & 1.4 & 0.7 & 5.8 & 17.3 & 0.5 & 1.4 & 83 \\
\hline Germany & 16.9 & 34.3 & 2.5 & 19.5 & 1 & 2.2 & 1 & 6.7 & 1.4 & 1.6 & 21.6 & 1.3 & 88 \\
\hline Switzerland & 15.3 & 36.3 & 4.6 & 22.6 & 0.4 & 2.6 & 1.3 & 0.7 & 3.3 & 0.2 & 6.1 & 16.7 & 93 \\
\hline Connectedness to others & 143 & 288 & 43 & 132 & 9 & 23 & 5 & 14 & 31 & 10 & 12 & 10 & 721 \\
\hline Connectedness incl. own & 230 & 368 & 85 & 163 & 95 & 53 & 70 & 62 & 92 & 27 & 34 & 26 & Total Connectedness $=55.16 \%$ \\
\hline
\end{tabular}

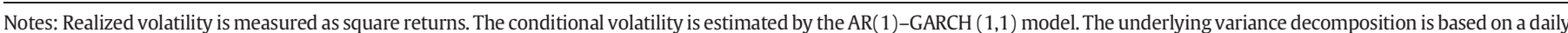

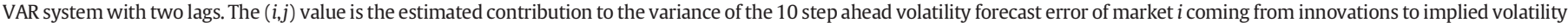

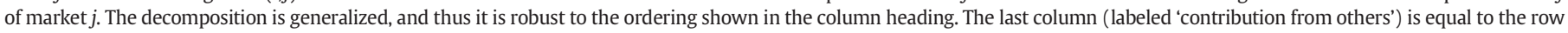

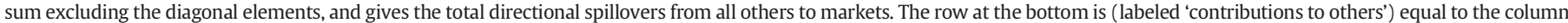

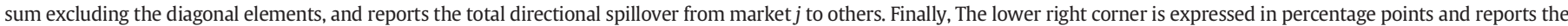
total volatility spillover index which equal to the grand off-diagonal column sum relative to the grand column sum including diagonals.

market and a group of global equity markets. The inference in this paper is different in that it is based on a more accurate measure of risk that reflects the consensus of the market on oil and equity volatilities. Hence, in this study, we are interested in inferring from the relationships that are implied by the market prices of oil and equity options. Moreover, compared to previous studies, our methods are more revealing and the directional connectedness measures are more informative about which markets are important to establish the linkages and on how these linkages are changing over time.

In particular, we studied the connectedness between the oil implied volatility and the implied volatility of equities in eleven major equity markets in the period that followed the 2008 financial crisis. It is also worth to mention that scarce studies examine the oil equity relationship during this period. ${ }^{42}$ Our results indicate that the oil market is playing the dominant role in the oil equity volatility relationship. The transmission mechanism of information is skewed in that the information transmission from oil to equities is larger than the transmission in the opposite direction. Moreover, the pattern of transmission is found to be time varying with large transmissions in the period that extends from the mid of 2009 to the mid of 2012 or during the global recovery. This implies that oil uncertainty matters more to equities at initial stages of recovery when the economic growth is fragile. It also implies that equity options cannot be priced in isolation of the uncertainty

\footnotetext{
42 For instance, see Mollick and Assefa (2013), Awartani and Maghyereh (2013), and Tsai
} (2015). that is perceived in the oil market particularly during periods of recovery.

We recognize here the limitation of the short length of the period under study due to the data availability. However, there are clear advantages of using implied volatility over historical volatility in analyzing the risk transfer between oil and equities. For instance, we find that the analysis based on implied volatility distinguishes more between risk transmission from oil to oil-producing countries as opposed to non-oil producing countries. It also differentiates the patterns of risk transfer to developing countries versus developed countries. The extra information disappear when historical volatility measures are used.

These results are important for investors who have exposures to oil and equity derivatives such as hedge funds. These investors assume non-linear exposures that are sensitive to volatility and options. For instance, the strong linkages between oil and equity imply less diversification benefits of including oil and equity options in a derivative portfolio, particularly when the underlying companies operate in an oil producing country.

The evidence on the connectedness between implied volatilities of oil and equities constitutes useful information for energy risk management and asset pricing. For instance, the oil equity implied volatility connectedness implies that oil price uncertainty cannot be ignored as a major factor in building a valuation model of equity options. Accounting for the connectedness may also help in constructing more accurate models in forecasting both equity volatility and oil volatility. Finally, policy-makers should be aware of the fact that oil uncertainty is quite 


\section{A Realized volatility}

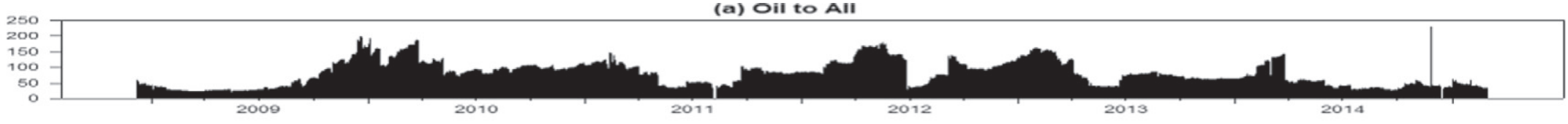

(b) All to oll

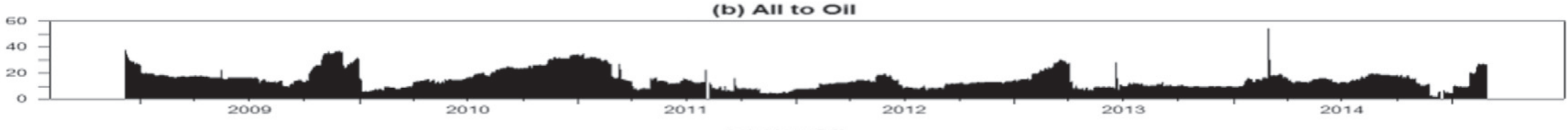

(c) Net OII

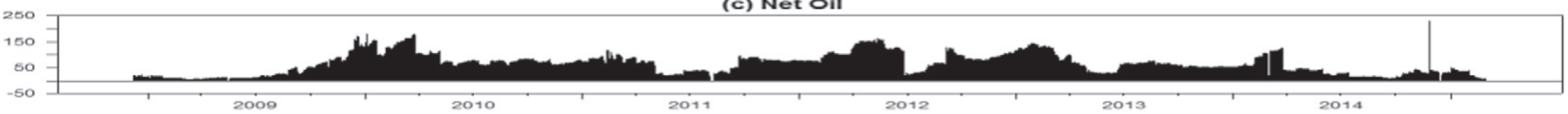

\section{B Conditional volatility}

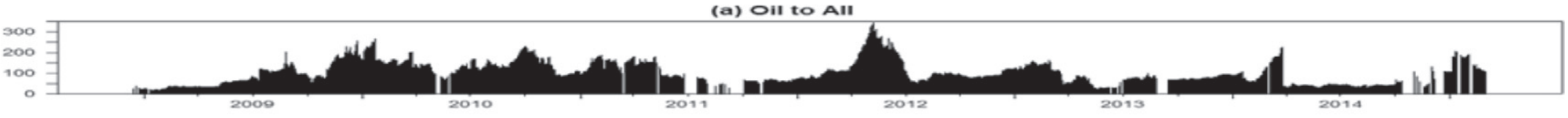

(b) All to oll

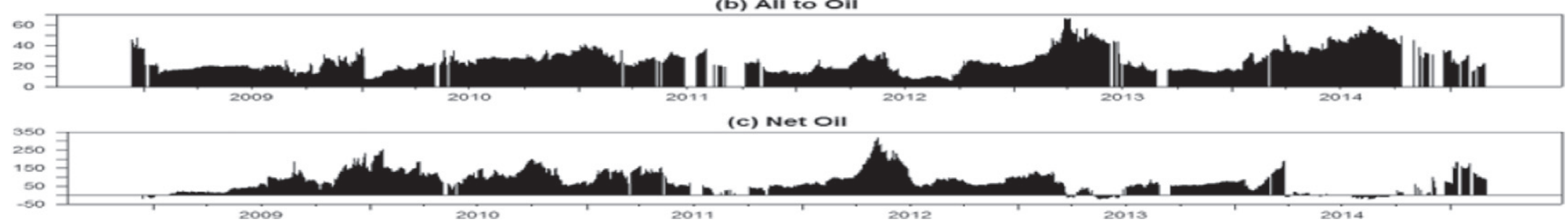

Notes: This figure shows the directional volatility connectedness from oil to all markets using two alternative volatility measures (realized and conditional volatility) over the sample period of $3^{\text {rd }}$ of March, 2008 to $3^{\text {rd }}$ of February, 2015 estimated with a rolling window of $200-d a y$. The predictive horizon of the underlying variance decomposition is 10-days ahead. 
Table 5

Granger causality test for implied volatility indices.

\begin{tabular}{|c|c|c|}
\hline Null hypothesis & F-statistic & Causality decision \\
\hline US does not Granger Cause Crude oil & $3.0546^{* * *}(0.0095)$ & Crude oil $\leftrightarrow$ USA \\
\hline Crude oil does not Granger Cause USA & $10.885^{* * *}(0.0000)$ & \\
\hline Canada does not Granger Cause Crude oil & $1.6590(0.1413)$ & Crude oil $\rightarrow$ Canada \\
\hline Crude oil does not Granger Cause Canada & $7.7465^{* * *}(0.0000)$ & \\
\hline UK does not Granger Cause Crude oil & $2.0640 *(0.0672)$ & Crude oil $\rightarrow$ UK \\
\hline Crude oil does not Granger Cause UK & $9.2530^{* * * *}(0.0000)$ & \\
\hline India does not Granger Cause Crude oil & $0.8368(0.5235)$ & Crude oil $\rightarrow$ India \\
\hline Crude oil does not Granger Cause India & $8.0711^{* * *}(0.0000)$ & \\
\hline Mexico does not Granger Cause Crude oil & $0.8299(0.5002)$ & Crude oil $\rightarrow$ Mexico \\
\hline Crude oil does not Granger Cause Mexico & $3.9265^{* * * *}(0.0015)$ & \\
\hline Japan does not Granger Cause Crude oil & $2.0637^{*}(0.0672)$ & Crude oil $\rightarrow$ Japan \\
\hline Crude oil does not Granger Cause Japan & $16.7325^{* * *}(0.0000)$ & \\
\hline Sweden does not Granger Cause Crude oil & $1.3674(0.1050)$ & Crude oil $\rightarrow$ Sweden \\
\hline Crude oil does not Granger Cause Sweden & $11.8314^{* * *}(0.0000)$ & \\
\hline Russia does not Granger Cause Crude oil & $1.0738(0.3729)$ & Crude oil $\rightarrow$ Russia \\
\hline Crude oil does not Granger Cause Russia & $3.6853^{* * *}(0.0025)$ & \\
\hline South Africa does not Granger Cause Crude oil & $0.5179(0.7630)$ & Crude oil $\rightarrow$ South \\
\hline Crude oil does not Granger Cause South Africa & $8.2805^{* * *}(0.0000)$ & Africa \\
\hline Germany does not Granger Cause Crude oil & $1.3133(0.1055)$ & Crude oil $\rightarrow$ Germany \\
\hline Crude oil does not Granger Cause Germany & $6.0684^{* * *}(0.0000)$ & \\
\hline Switzerland does not Granger Cause Crude oil & $1.4447(0.2051)$ & Crude oil $\rightarrow$ Switzerland \\
\hline Crude oil does not Granger Cause Switzerland & $7.8412^{* * *}(0.0000)$ & \\
\hline
\end{tabular}

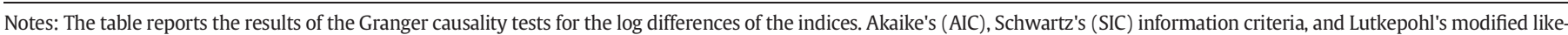

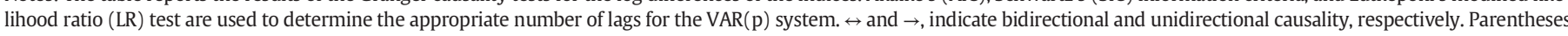
indicate the probability level.

*** Denotes significance at the $1 \%$ level.

* Denotes significance $10 \%$ level.

relevant and hence incorporate measures that increase equity markets resiliency to oil volatility shocks.

\section{Appendix A. Supplementary data}

Supplementary data to this article can be found online at http://dx. doi.org/10.1016/j.eneco.2016.04.010.

\section{References}

Akgiray, V., 1989. Conditional heteroscedasticity in time series of stock returns: evidence and forecasts. J. Bus. 55-80.

Antonakakis, N., 2012. Exchange return co-movements and volatility spillovers before and after the introduction of euro. J. Int. Financ. Mark. Inst. Money 22 (5), 1091-1109.

Apergis, N., Miller, S.M., 2009. Do structural oil-market shocks affect stock prices? Energy Econ. 31 (4), 569-575.

Arouri, M.E.H., Rault, C., 2012. Oil prices and stock markets in GCC countries: empirical evidence from panel analysis. Int. J. Financ. Econ. 17 (3), 242-253.

Arouri, M.E.H., Jouini, J., Nguyen, D.K., 2011. Volatility spillovers between oil prices and stock sector returns: implications for portfolio management. J. Int. Money Financ. 30 (7), 1387-1405.

Asteriou, D., Bashmakova, Y., 2013. Assessing the impact of oil returns on emerging stock markets: a panel data approach for ten central and eastern European countries. Energy Econ. 38, 204-211.

Awartani, B., Maghyereh, A.I., 2013. Dynamic spillovers between oil and stock markets in the Gulf cooperation council countries. Energy Econ. 36, 28-42.

Awartani, B., Maghyereh, A.I., Al Shiab, M., 2013. Directional spillovers from the US and the Saudi market to equities in the Gulf cooperation council countries. J. Int. Financ. Mark. Inst. Money 27, 224-242.

Bachmeier, L., 2008. Monetary policy and the transmission of oil shocks. J. Macroecon. 30 (4), $1738-1755$.

Basher, S.A., Sadorsky, P., 2006. Oil price risk and emerging stock markets. Glob. Financ. J. 17, 224-251.

Bentes, S.R., 2015. A comparative analysis of the predictive power of implied volatility indices and GARCH forecasted volatility. Physica A 424, 105-112.

Blair, B.J., Poon, S.H., Taylor, S.J., 2001. Modelling S\&P 100 volatility: the information content of stock returns. J. Bank. Financ. 25 (9), 1665-1679.

Bouri, E., 2015a. Oil volatility shocks and the stock markets of oil-importing MENA economies: a tale from the financial crisis. Energy Econ. 51, 590-598.

Bouri, E., 2015b. Return and volatility linkages between oil prices and the lebanese stock market in crisis periods. Energy 89, 365-371.

Bouri, E., Demirer, R., 2016. On the volatility transmission between global oil and stock markets: a comparison of emerging importers and exporters. Econ. Polit. 1-20 (http://link.springer.com/article/10.1007/s40888-016-0022-6).

Boyer, M.M., Fillion, D., 2007. Common and fundamental factors in stock returns of Canadian oil and gas companies. Energy Econ. 29, 428-453.
Brailsford, T.J., Faff, R.W., 1996. An evaluation of volatility forecasting techniques. J. Bank Financ. 20 (3), 419-438.

Broner, F.A., Gelos, R.G., Reinhart, C.M., 2006. When in peril, retrench: testing the portfolio channel of contagion. J. Int. Econ. 69 (1), 203-230.

Büyükşahin, B., Robe, M.A., 2014. Speculators, commodities and cross-market linkages. J. Int. Money Financ. 42, 38-70.

Carr, P., Wu, L., 2006. A tale of two indices. J. Deriv. 13, 13-29.

Chen, S.S., 2010. Do higher oil prices push the stock market into bear territory? Energy Econ. 32 (2), 490-495.

Christensen, B.J., Prabhala, N.R., 1998. The relation between implied and realized volatility. J. Financ. Econ. 50 (2), 125-150.

Cong, R.G., Wei, Y.M., Jiao, J.L., Fan, Y., 2008. Relationships between oil price shocks and stock market: an empirical analysis from China. Energy Policy 36 (9), 3544-3553.

Corrado, C.J., Miller, T.W., 2005. The forecast quality of CBOE implied volatility indexes. J. Futur. Mark. 25, 339-373.

Danielsson, J., Song Shin, H., Zigrand, J.P., 2011. Balance Sheet Capacity and Endogenous Risk. Working Paper. London School of Economics and Princeton University.

Diebold, F.X., Yilmaz, K., 2009. Measuring financial asset return and volatility spillovers, with application to global equity markets. Econ. J. 119 (534), 158-171.

Diebold, F.X., Yilmaz, K., 2012. Better to give than to receive: predictive directional measurement of volatility spillovers. Int. J. Forecast. 28 (1), 57-66.

Diebold, F.X., Yilmaz, K., 2014. On the network topology of variance decompositions: measuring the connectedness of financial firms. J. Econ. 182 (1), 119-134.

Diebold, F.X., Yilmaz, K., 2015. Financial and Macroeconomic Connectedness: a Network Approach to Measurement and Monitoring. Oxford University Press.

Driesprong, G., Jacobsen, B., Maat, B., 2008. Striking oil: another puzzle? J. Financ. Econ. 89 (2), 307-327.

El-Sharif, I., Brown, D., Burton, B., Nixon, B., Russell, A., 2005. Evidence on the nature and extent of the relationship between oil prices and equity values in the UK. Energy Econ. 27 (6), 819-830.

Figlewski, S., 1997. Forecasting volatility. Financ. Mark. Inst. Instrum. 6 (1), 1-88.

Fleming, J., 1998. The quality of market volatility forecasts implied by S\&P 100 index option prices. J. Empir. Financ. 5, 317-345.

Foster, D.P., Nelson, D.B., 1996. Continuous record asymptotics for rolling sample variance estimators. Econometrica 64 (1), 139-174.

Franses, P.H., Van Dijk, D., 1996. Forecasting stock market volatility using (nonlinear) GARCH models. J. Forecast. 229-235.

Gonzalez-Perez, M.T., 2015. Model-free volatility indexes in the financial literature: A review. Int. Rev. Econ. Financ. 40, 141-159.

Hammoudeh, S., Aleisa, E., 2004. Dynamic relationships among GCC stock markets and NYMEX oil futures. Contemp. Econ. Policy 22 (2), 250-269.

Huang, R.D., Masulis, R.W., Stoll, H.R., 1996. Energy shocks and financial markets. J. Futur. Mark. 16 (1), 1-27.

Jones, C.M., Kaul, G., 1996. Oil and the stock markets. J. Financ. 51 (2), 463-491.

Jorion, P., 1995. Predicting volatility in the foreign exchange market. J. Financ. 50 (2) 507-528.

Kilian, L., 2008. Exogenous oil supply shocks: how big are they and how much do they matter for the US economy? Rev. Econ. Stat. 90 (2), 216-240. 
Kling, J.I., 1985. Oil price shocks and stock market behaviour. J. Portf. Manag. 12 (1), 34-39.

Klößner, S., Wagner, S., 2014. Exploring all VAR orderings for calculating spillovers? Yes, we can!-a note on Diebold and Yilmaz (2009). J. Appl. Econ. 29 (1), 172-179.

Kodres, L.E., Pritsker, M., 2002. A rational expectations model of financial contagion. J. Financ. 57 (2), 769-799.

Koop, G., Pesaran, M.H., Potter, S.M., 1996. Impulse response analysis in nonlinear multivariate models. J. Econ. 74, 119-147.

Kyle, A.S., Xiong, W., 2001. Contagion as a wealth effect. J. Financ. 56 (4), 1401-1440.

Maghyereh, A., 2004. Oil price shocks and emerging stock markets: a generalized VAR approach. Int. J. Appl. Econ. Quant. Stud. 1 (2), 27-40.

Maghyereh, A., Al-Kandari, A., 2007. Oil prices and stock markets in GCC countries: new evidence from nonlinear Cointegration analysis. Manag. Financ. 33 (7), 449-460.

Maghyereh, A., Awartani, B., 2016. Oil price uncertainty and equity returns: evidence from oil importing and exporting countries in the MENA region. J. Financ. Econ. Policy 8 (1), 64-79.

Maghyereh, A., Awartani, B., Al Hilu, K., 2015. Dynamic transmissions between the US and equity markets in the MENA countries: new evidence from pre-and post-global financial crisis. Q. Rev. Econ. Financ. 56, 123-138.

Malik, F., Ewing, B.T., 2009. Volatility transmission between oil prices and equity sector returns. Int. Rev. Financ. Anal. 18 (3), 95-100.

Malik, F., Hammoudeh, S., 2007. Shock and volatility transmission in the oil, US and gulf equity markets. Int. Rev. Econ. Financ. 16 (3), 357-368.

Masih, R., Peters, S., De Mello, L., 2011. Oil price volatility and stock price fluctuations in an emerging market: evidence from South Korea. Energy Econ. 33 (5), 975-986.

McMillan, D.G., Speight, A.E., 2010. Return and volatility spillovers in three euro exchange rates. J. Econ. Bus. 62 (2), 79-93.

Mollick, A.V., Assefa, T.A., 2013. US stock returns and oil prices: the tale from daily data and the 2008-2009 financial crisis. Energy Econ. 36, 1-18.

Nandha, M., Brooks, R., 2009. Oil price and transport sector returns: an international analysis. Rev. Quant. Finan. Acc. 33, 393-409.
Nandha, M., Faff, R., 2008. Does oil move equity prices? A global view. Energy Econ. 30 (3), 986-997.

Nandha, M., Hammoudeh, S., 2007. Systematic risk, and oil price and exchange rate sensitivities in Asia-Pacific stock markets. Res. Int. Bus. Financ. 21 (2), 326-341.

Narayan, P.K., Narayan, S., 2010. Modelling the impact of oil prices on Vietnam's stock prices. Appl. Energy 87, 356-361.

Papapetrou, E., 2001. Oil price shocks, stock market, economic activity and employment in Greece. Energy Econ. 23 (5), 511-532.

Park, J., Ratti, R.A., 2008. Oil price shocks and stock markets in the US and 13 European countries. Energy Econ. 30 (5), 2587-2608.

Pavlova, A., Rigobon, R., 2008. The role of portfolio constraints in the international propagation of shocks. Rev. Econ. Stud. 75 (4), 1215-1256.

Pesaran, M.H., Shin, Y., 1998. Generalized impulse response analysis in linear multivariate models. Econ. Lett. 58, 17-29.

Poon, S., Granger, C.W.R., 2003. Forecasting volatility in financial markets: A review. J. Econ. Lit. 66, 478-539.

Sadorsky, P., 1999. Oil price shocks and stock market activity. Energy Econ. 21 (5), 449-469.

Sadorsky, P., 2001. Risk factors in stock returns of Canadian oil and gas companies. Energy Econ. 23, 17-28.

Sari, R., Hammoudeh, S., Soytas, U., 2010. Dynamics of oil price, precious metal prices, and exchange rate. Energy Econ. 32 (2), 351-362.

Triacca, U., 2007. On the variance of the error associated to the squared return as proxy for volatility. Appl. Financ. Econ. Lett. 3 (255-27).

Tsai, C.L., 2015. How do US stock returns respond differently to oil price shocks pre-crisis, within the financial crisis, and post-crisis? Energy Econ. 50, 47-62.

Wang, Y., Wu, C., Yang, L., 2013. Oil price shocks and stock market activities: evidence from oil-importing and oil-exporting countries. J. Comp. Econ. 41 (4), 1220-1239.

Whaley, R.E., 2008. Understanding Vix (Available at SSRN 1296743). 